\title{
Exportações Internacionais e Interações Regionais: Uma Análise de Equilíbrio Geral ${ }^{\star}$
}

\author{
- Fernando Salgueiro Perobell * - Eduardo amaral Haddad * *
}

\begin{abstract}
RESUMO
O comércio pode ser um importante estímulo para o rápido crescimento econômico, embora muitas vezes, não seja uma estratégia desejável para o desenvolvimento econômico e social. A contribuição do comércio para o desenvolvimento depende, dentre outros fatores, da natureza do setor exportador, da distribuição de seus benefícios e dos linkages dos setores exportadores com os demais setores da economia. No período recente, entretanto, os analistas regionais têm se preocupado com questões inerentes ao comércio internacional devido, dentre outros fatores, ao processo de globalização e à hipótese de que o crescimento de uma região está diretamente relacionado com a sua habilidade em competir no mercado internacional. Portanto, um modelo interestadual de EGC é implementado neste trabalho a fim de simular quais as prováveis implicações do crescimento das exportações internacionais estaduais para a estrutura de interações inter-regionais brasileiras (e.g exportações inter-regionais).
\end{abstract}

\section{Palavras-CHave}

desenvolvimento regional, equilíbrio geral computável, comércio

\begin{abstract}
Trade can be an important stimulus to rapid economic growth, although it might not be a desirable strategy for economic and social development. The contribution to development depends on the nature of the export sector, the distribution of its benefits, and the sector's linkages with the rest of the economy Recently, however, given the focus on globalization issues and the implicit assumption that a region's economic future is inextricably tied with its ability to compete in the international export market, international trade has attracted the attention of regional analysts as well. In this paper we address some of these issues. An interstate CGE model is implemented to simulate the likely implications of state export growth on the structure of the Brazilian economic interregional system.
\end{abstract}

\section{KEY WORDS}

regional development, computable general equilibrium, trade

\section{JEL CLASSIFICATION}

$R / I, R / 3$

+ O primeiro autor agradece o apoio financeiro da CAPES e o segundo agradece o apoio financeiro do CNPq.

* Doutor FEA/USP. Professor Adjunto FEA/UFJF. Coordenador do Mestrado em Economia Aplicada FEA/UFJF. E-mail: fernando.perobelli@ufjf.edu.br. Endreço para contato: Universidade Federal de Juiz de Fora - Faculdade de Economia e Administração - Cidade Universitária - Juiz de Fora - MG - CEP 36036-330.

** PhD University of Illinois. Professor FEA/USP. E-mail: ehaddad@usp.br. Endereço para contato: Departamento de Economia - FEA-USP - Av. Prof. Luciano Gualberto, 908. São Paulo - SP - CEP 05508-0I0.

(Recebido em agosto de 2005. Aceito para publicação em fevereiro de 2006). 


\section{INTRODUÇÃO}

O processo de ajuste pelo qual a economia brasileira tem passado nos últimos anos é, em parte, resultante dos impactos da globalização, dos acordos de comércio e da criação de áreas de livre comércio, como, por exemplo, a criação do Mercosul em 1990. Mais recentemente, o Brasil tem participado, no âmbito do Mercosul, da negociação de um acordo comercial entre o Mercosul e a União Européia. O País está também diretamente envolvido nas negociações para a criação da Área de Livre Comércio das Américas (ALCA). Dentre os vários ajustes que têm ocorrido na economia brasileira pode-se destacar a mudança no comportamento dos fluxos de comércio do País. Um outro ponto a ser ressaltado, no âmbito das mudanças recentes da economia brasileira, é o possível impacto espacialmente diferenciado do processo de globalização econômica mundial. Isto pode ocorrer devido à existência de especificidades regionais, principalmente no que se refere à composição da estrutura setorial, à disponibilidade de fatores produtivos, ao processo de inovação tecnológica das empresas e ao grau de interação regional.

O processo de globalização (e o concomitante processo de fortalecimento dos blocos de comércio) tem proporcionado mudanças em relação ao fluxo de mercadorias e serviços entre os países. Em outras palavras, o advento da globalização torna-se determinante no processo recente de mudança das relações comerciais. Portanto, o processo de desenvolvimento de economias periféricas, como a brasileira, está ocorrendo num ambiente de crescente integração. Para sustentar o processo desenvolvido ora implementado faz-se necessário inserir, de forma competitiva, a economia brasileira nos fluxos dinâmicos do comércio e dos investimentos.

Aliado ao panorama de mudanças no contexto internacional, o estudioso da questão regional no Brasil se depara com a seguinte dicotomia: promoção do crescimento regional de forma a diminuir as disparidades ainda existentes no Brasil e necessidade de inserção da economia brasileira na economia mundial. A maior inserção da economia brasileira no contexto internacional está centrada na necessidade de um aumento da competitividade, de uma diminuição de custos e da reestruturação produtiva. Cabe ressaltar que esse processo pode reforçar os desequilíbrios regionais e ainda criar dificuldades de desenvolvimento em áreas consideradas dinâmicas.

Portanto, tomando por base a idéia de aumento dos fluxos de comércio como propulsor do crescimento regional, e a questão da heterogeneidade espacial do desenvolvimento brasileiro, abre-se espaço para o desenvolvimento de instrumentos analíticos eficazes que permitam avaliar os efeitos das políticas de integração sobre as macrorregiões brasileiras e unidades da Federação. 
O objetivo principal deste trabalho é contribuir para o melhor entendimento das interações econômicas ${ }^{1}$ das unidades da Federação. Perobelli e Haddad $(2003 a, b)$ analisam, de forma detalhada, a estrutura das interações entre as unidades da Federação, para o ano de 1996, sob a ótica interna (i.e interdependência intra-regional e interregional). Em outras palavras, trata de questões inerentes ao padrão de distribuição espacial do comércio, dependência macrorregional e inter-regional. Perobelli (2004) também analisa as interações sob a ótica externa, ou seja, a inserção das unidades da Federação no comércio internacional. Os trabalhos acima mencionados discutem a heterogeneidade espacial das interações e contribuem para o melhor entendimento da estrutura de interações das unidades da Federação, mas estudam o comércio das unidades da Federação separadamente.

O presente trabalho possibilitará efetuar uma análise integrada das interações (exportações internacionais e exportações inter-regionais). Esta consiste em, por exemplo, verificar qual o impacto de um aumento das transações internacionais (i.e exportaçóes internacionais) de um setor localizado em determinada unidade da Federação sobre as exportações internas das demais unidades da Federação. Portanto, lida com questóes inerentes à interdependência entre exportações que têm como destino o exterior e aquelas que têm como destino as demais unidades da Federação, distribuição espacial e concentração e/ou dispersão regional dos fluxos de comércio, mensurado no presente trabalho via exportações.

Ao fazer a análise integrada das interações por meio de um modelo de equilíbrio geral computável (EGC) pode-se levar em conta a possibilidade de substituição entre bens domésticos e importados, a variação nos preços relativos, a possibilidade de substituição diferenciada para os bens de exportação, dentre outros. Resta ainda ressaltar que para analisar a interdependência entre setores, regióes e famílias de forma mais acurada é importante levar em conta fatores diversos, como diferenciais de preço e mobilidade dos fatores de produção, entre outros. Portanto, a estrutura de EGC parece-nos mais adequada para tratar, de forma completa, as interações espaciais entre as unidades da Federação.

Assim sendo, o tratamento de forma integrada das interações das unidades da Federação na estrutura de EGC é implementado, neste trabalho, por meio do modelo B-MARIA27-IT. O exercício de simulação representa um aumento das exportações, ou seja, um deslocamento na curva de demanda por exportações para os diversos blocos de comércio. A estrutura do modelo B-MARIA27-IT permite verificar qual o mecanismo de transmissão desse choque na estrutura de interações entre as unidades da Federação e qual o impacto do aumento das interaçóes com o setor externo para

1 Cabe ressaltar que as interações serão tratadas neste trabalho como o comércio entre as diversas unidades espaciais e suas relaçóes de comércio com o resto do mundo. Ênfase será dada ao setor exportador. 
a estrutura econômica das unidades da Federação (i.e. produto, balança comercial, fluxos de comércio inter-regional e internacional).

É importante salientar que a análise integrada das interações permite testar a hipótese de que os impactos das variações no destino das exportações das unidades da Federação são diferenciados espacialmente. O deslocamento da curva de demanda por exportações para os cinco blocos de comércio explicitados no modelo B-MARIA27IT (Mercosul, União Européia, Nafta, resto da ALCA e resto do mundo) se insere no contexto recente da economia brasileira, ou seja, busca estratégias diferenciadas de integração regional a fim de reforçar os impulsos para o crescimento econômico. Em outras palavras, caracteriza as modificações recentes das relações comerciais brasileiras, as quais se inserem num contexto crescente de regionalismo.

Para implementar tal análise este trabalho está estruturado da seguinte forma: além desta parte introdutória, apresenta na seção 1 a metodologia implementada, na seção 2 o modelo, na seção 3 discute os principais resultados e na última seção apresenta algumas conclusões.

\section{O MODELO B-MARIA27-IT}

Para mensurar os efeitos de curto prazo de variações nas exportações internacionais das unidades da Federação sobre a estrutura de exportações regionais foi desenvolvido e implementado um modelo interestadual de equilíbrio geral computável (BMARIA27-IT). Em outras palavras, a estrutura do modelo permite verificar quais são os efeitos de curto prazo de um aumento das relações das unidades da Federação com o setor externo sobre a estrutura interna de interaçóes (e.g exportaçóes para as demais unidades da Federação). A estrutura do modelo é uma extensão do modelo BMARIA27. (Haddad et al., 2003). O modelo também utiliza a estrutura dos modelos SPARTA (Domingues, 2002) e do modelo EFES-IT (Haddad et al., 2002).

O modelo é formado pelos seguintes agentes: setores produtivos, investidores, famílias, governo federal, governo regional e setor externo. Existem 8 setores $^{2}$ que são responsáveis pela produção de 8 bens em cada uma das 27 unidades da Federação. $\mathrm{O}$ setor externo é dividido em cinco regiões: NAFTA, resto da ALCA, União Européia, Mercosul e resto do mundo.

A estrutura matemática do modelo B-MARIA27-IT toma como base o modelo MONASH-MRF (Peter et al., 1996) para a economia australiana. O modelo

2 Agropecuária (1), indústria de transformação (2), S.I.U.P (3), construção (4), comércio (5), instituições financeiras (6), administração pública (7) e outros serviços (8). 
B-MARIA27-IT pertence à classe dos modelos do tipo Johansen, em que as soluções são obtidas a partir de um sistema de equações linearizadas. Um resultado típico mostra a variação porcentual no conjunto de variáveis endógenas, após a implementação de uma política econômica, comparada aos seus valores na ausência de tal política, em dado ambiente econômico. A apresentação esquemática das soluções de Johansen para tais modelos é padrão na literatura. Mais detalhes podem ser encontrados em Dixon et al. (1992). A estrutura completa de equações e parâmetros do modelo está apresentada no Apêndice.

\subsection{Fechamento}

O modelo B-MARIA27-IT contém 706.659 equações e 728.189 variáveis. Portanto, para fechar o modelo é necessário exogeneizar 21.530 variáveis. A fim de captar os efeitos de primeira ordem de um aumento das relações entre as unidades da Federação e o setor externo as simulações foram implementadas utilizando um fechamento básico de curto prazo. Além da imobilidade interindustrial e inter-regional do capital, o fechamento de curto prazo toma a população regional e a oferta de trabalho como fixas, o diferencial regional de salário também é fixo, assim como o salário real nacional. O emprego regional é função das hipóteses sobre taxas de salário, que indiretamente determinam as taxas de desemprego regionais. Segundo Haddad (1999) as hipóteses anteriormente especificadas visam captar, da maneira mais próxima possível, a realidade de funcionamento do mercado de trabalho brasileiro. Portanto, as mudanças na demanda de trabalho trazem impactos sobre o desemprego, em vez de mudanças no salário real. Um outro ponto importante é que a imobilidade inter-regional do trabalho no curto prazo indica que a decisão de migrar não é uma decisão de curto prazo. Por fim, os diferenciais de salários no Brasil são persistentes, refletindo a segmentação geográfica da força de trabalho. Pelo lado da demanda, os gastos com investimento são exógenos, conseqüientemente, as firmas não podem reavaliar as decisões de investimento no curto prazo. O consumo das famílias é uma função da renda disponível, e o consumo do governo, tanto federal como regional, é fixo. Para permitir variações nos gastos do governo pode-se determinar exogenamente o déficit do governo. Uma vez que o modelo não apresenta nenhuma teoria sobre crescimento endógeno, as variáveis de choque tecnológico são consideradas exógenas.

Cabe ressaltar que as formas funcionais das principais equações do modelo, as principais variáveis e coeficientes estão apresentadas no apêndice. 


\subsection{Calibragem}

O modelo é calibrado para 1996, pois: a) este é o ano de publicação da última matriz de insumo-produto do IBGE; e b) Haddad et al. (2002) construíram um sistema de contas estaduais para o Brasil, para o ano de 1996, com base nas informações estaduais disponíveis para o PIB (IBGE, 2001), receitas e despesas governamentais (IBGE, 2000), comércio internacional (MDIC, 2001), comércio interestadual (Secretaria da Fazenda - CONFAZ). Tais informações permitiram a estimação do consumo e investimento por unidade da Federação. Assim sendo, uma vez conhecidas as contas estaduais e a matriz nacional de insumo-produto, estimou-se a matriz interestadual de insumo-produto, com detalhamento para oito setores.

Portanto, os dados das contas estaduais e a matriz nacional de insumo-produto de 1996 (IBGE, 1997) representam as informações completas mais recentes necessárias para a estimação da matriz interestadual de insumo-produto. Cabe ressaltar que, em uma primeira etapa, os resultados foram apurados de forma agregada para as unidades da Federação como um todo, não sendo fornecidas informações setoriais. A etapa seguinte consistiu na passagem do nível agregado para um detalhamento setorial. Para que as informações agregadas possam ser utilizadas em conjunto com as Contas Regionais (IBGE, 2001) e dados da PNAD, uma agregação de produtos e setores é necessária. Inicialmente, transforma-se o sistema produto $\mathrm{x}$ setor em um sistema setor x setor, por meio da matriz de market-share (Ramos, 1997), a partir de informações do sistema de insumo-produto para o Brasil. Em seguida, uma agregação para os oito setores considerados na matriz interestadual é efetuada, conforme pode ser observado na Tabela 1. Desta forma, todas as informações nacionais a serem utilizadas são compatibilizadas setorialmente com as informações obtidas das Contas Regionais. Cabe ressaltar que o detalhamento para oito setores baseia-se em uma limitação no que tange à disponibilidade de dados. Como as duas principais fontes de dados utilizadas para proceder à desagregação da matriz nacional em uma matriz inter-regional (27 regiões) são a) a matriz de insumo-produto nacional de 1996, publicada pelo IBGE e b) as informaçóes de valor adicionado (VA), valor bruto da produção (VBP) e consumo intermediário (CI) para as 27 unidades da Federação, publicada pelo IBGE (Contas Regionais), que destacam 13 setores produtivos, optou-se por tal agregação, que como afirmado anteriormente está apresentada na Tabela 1.

Assim sendo, para calibrar o modelo foram utilizados dados da matriz de absorção e parâmetros relativos a elasticidades de substituição entre fatores primários, elasticidades de substituição no comércio inter-regional e internacional do tipo Armington, taxas de depreciação, taxas de juro internacional, coeficiente dívida externa e PIB, elasticidades-gasto consumo das famílias, dentre outras. Estes foram retirados da literatura (ver Dixon et al., 1997; Haddad e Domingues, 2001; e Haddad e Hewings, 
1997). Já os valores das elasticidades das exportações ${ }^{3}$ foram estimados econometricamente para o setor agropecuário e industrial e para os demais setores foram obtidos em Haddad e Domingues (2001). ${ }^{4}$

Cabe ressaltar que a construção das matrizes de comércio intersetoriais e interestaduais seguiu a tradição de desagregação de matrizes regionais de insumo-produto, ou seja, regionalização da matriz de coeficientes técnicos e demanda final por meio do método de quociente locacional e posterior comparação dos resultados com os dados da balança comercial interestadual. (CONFAZ, 1997). Vale mencionar que este procedimento está descrito de forma completa em Hulu e Hewings (1993) e Miller e Blair (1985). Aplicações desta metodologia para o Brasil podem ser encontradas em Haddad e Hewings (1998), Haddad (1999) e Domingues (2002).

\section{TABELA 1 - COMPATIBILIZAÇÃO SETORIAL}

\begin{tabular}{|c|c|c|c|c|}
\hline \multicolumn{2}{|c|}{$\begin{array}{l}\text { Setor na Matriz } \\
\text { Interestadual }\end{array}$} & \multicolumn{2}{|c|}{$\begin{array}{l}\text { Setor nas Contas } \\
\text { Regionais }\end{array}$} & \multirow{2}{*}{$\begin{array}{l}\text { Setor nas Contas } \\
\text { Nacionais } \\
1\end{array}$} \\
\hline 1 & Agropecuária & 1 & Agropecuária & \\
\hline \multirow{2}{*}{2} & \multirow{2}{*}{$\begin{array}{l}\text { Indústria de } \\
\text { Transformação }\end{array}$} & 2 & Ind. Extrativa Mineral & 2 a 3 \\
\hline & & 3 & Ind. Transformação & 4 a 32 \\
\hline 3 & S.I.U.P. & 4 & Eletricidade, Gás e Água & 33 \\
\hline 4 & Construção & 5 & Construção & 34 \\
\hline 5 & Comércio & 6 & Comércio & 35 \\
\hline 6 & Instituições Financeiras & 7 & Intermediação Financeira & 36 \\
\hline \multirow[t]{3}{*}{7} & \multirow[t]{3}{*}{ Administração Pública } & 8 & Administração Pública & 37 \\
\hline & & 9 & Comunicações & 38 \\
\hline & & 10 & Serviços Prestados às Famílias & 39 \\
\hline \multirow[t]{3}{*}{8} & \multirow[t]{3}{*}{ Outros serviços } & 11 & Aluguéis e Serviços Prestados às Empresas & 40 a 41 \\
\hline & & 12 & Serviços Privados não-mercantis & 42 \\
\hline & & 13 & Transporte e Armazenagem & 43 \\
\hline
\end{tabular}

3 Devido à importância desses parâmetros para mensurar a interação entre o comércio externo e o comércio interno foi implementada uma avaliação de sensibilidade dos resultados em relação a esse conjunto de elasticidades.

4 Para mais detalhes sobre a importância da determinação dos parâmetros nos modelos de equilíbrio geral computável, ver Shoven e Whalley (1992). 


\section{RESULTADOS DAS SIMULAÇÕES ${ }^{5}$}

Nesta seção apresentam-se os principais resultados da simulação. O experimento básico consiste em: a) mudança na curva de demanda por exportação industrial para o Mercosul; b) mudança na curva de demanda por exportação industrial para a União Européia; c) mudança na curva de demanda por exportação industrial para o NAFTA; d) mudança na curva de demanda por exportação agropecuária para o Mercosul; e e) mudança na curva de demanda por exportação agropecuária para a União Européia. Tais simulaçóes podem ser entendidas como uma proxy que representaria o aumento das relações entre as unidades da Federação e o setor externo. Este exercício nos possibilitará verificar qual será o impacto, sobre as exportações interestaduais, de um aumento nas exportações internacionais de cada unidade da Federação. Em outras palavras, pode-se verificar qual será a distribuição dos benefícios das exportações.

\subsection{Mecanismo de Ajuste da Simulação}

O choque implementado no modelo consiste em deslocar a curva de demanda por exportação, o que representa um aumento dos fluxos de comércio em direção ao setor externo, que pode ocorrer devido a um aumento da renda nos blocos econômicos. Este aumento de renda amplia a demanda por exportações brasileiras, por hipótese, em $1 \%$. O deslocamento da demanda por exportações tem consequiências sobre a alocação da produção na economia (i.e consumo intermediário e absorção interna) e sobre o produto final da economia (PIB).

A equação (l) representa a demanda externa por bens domésticos. Portanto, a simulação implementada neste trabalho é representada por um aumento de $1 \%$ no termo de deslocamento, para quantidades, na curva de demanda por exportações $\left(f q_{(i s)}^{(4) r}\right)$.

$$
\left(x_{(i s)}^{(4) r}-f q_{(i s)}^{(4) r}\right)=\eta_{(i s)}^{r}\left(p_{(i s)}^{(4) r}-e-f p_{(i s)}^{(4) r}\right), \quad i=1, \ldots, g ; s=1 b, 2 \text { para } b=1, \ldots, q ; r=1, \ldots, R
$$

As consequiências imediatas podem ser descritas da seguinte forma: ${ }^{6}$

a) impacto sobre a curva de demanda por exportação $-\left(x_{(i s)}^{(4) r}\right)$, ou seja, variações no volume de exportação. Deve-se salientar que a magnitude da variação no volume de exportação depende também diretamente dos preços dos produtos exportados - $\left.\left(p_{(i s)}^{(4) r}\right)\right)$ e da elasticidade da demanda de exportação - $\left(\eta_{(i s)}^{r}\right)$; o preço dos produ-

5 Os resultados das simulações foram calculados no software GEMPACK. (Harrison and Person, 1994, 1996).

6 Cabe ressaltar que os pontos $a, b, c$ e $d$ são uma simples forma de descrição dos encadeamentos que ocorrem após a implementação do choque. Não significam uma seqüência de acontecimentos, pois em equilíbrio geral as modificações nos diversos mercados e equações ocorrem de forma simultânea. 
tos exportados é afetado pelos custos internos de produção, que dependem do preço relativo dos fatores e dos insumos de produção;

b) a variação no volume de exportação $-\left(x_{(i s)}^{(4) r}\right)$ tem impacto direto sobre o equilíbrio entre oferta e demanda no mercado de bens não margens;

c) ajuste no mercado de bens não margens pelo lado da oferta. O ajuste pode ser explicado da seguinte maneira: o deslocamento da curva de demanda por exportação pode ser entendido como um aumento da "preferência" por ofertar os bens fora do país em vez de ofertá-los internamente. Contudo, cabe ressaltar que essa realocação das vendas pode estar sendo limitada por restrições de oferta, ou seja, pela capacidade de produção, e pela elevação dos custos de produção (no fechamento de curto prazo do modelo o investimento e o estoque de capital são fixos). Logo, pode ocorrer um ajuste sobre consumo, investimento (apenas no longo prazo) e gastos do governo (absorção interna) e sobre os fluxos inter-regionais. É relevante salientar que o ajuste nos fluxos inter-regionais depende da estrutura de interações entre as unidades da Federação, pois, para determinada região, suprir essa variação positiva na demanda por exportação pode significar a necessidade de adquirir insumos de outras unidades. Logo, o ajuste no consumo intermediário pode ser tanto negativo quanto positivo;

d) Um outro impacto direto da variação no volume de exportação - $\left.\left(x_{(i s)}^{(4) r}\right)\right)$ - são as variações no preço, em moeda estrangeira, dos bens exportados.

\section{FIGURA I - MECANISMO DE AJUSTE DA SIMULAÇÃO - PRINCIPAIS RELAÇÕES CAUSAIS}

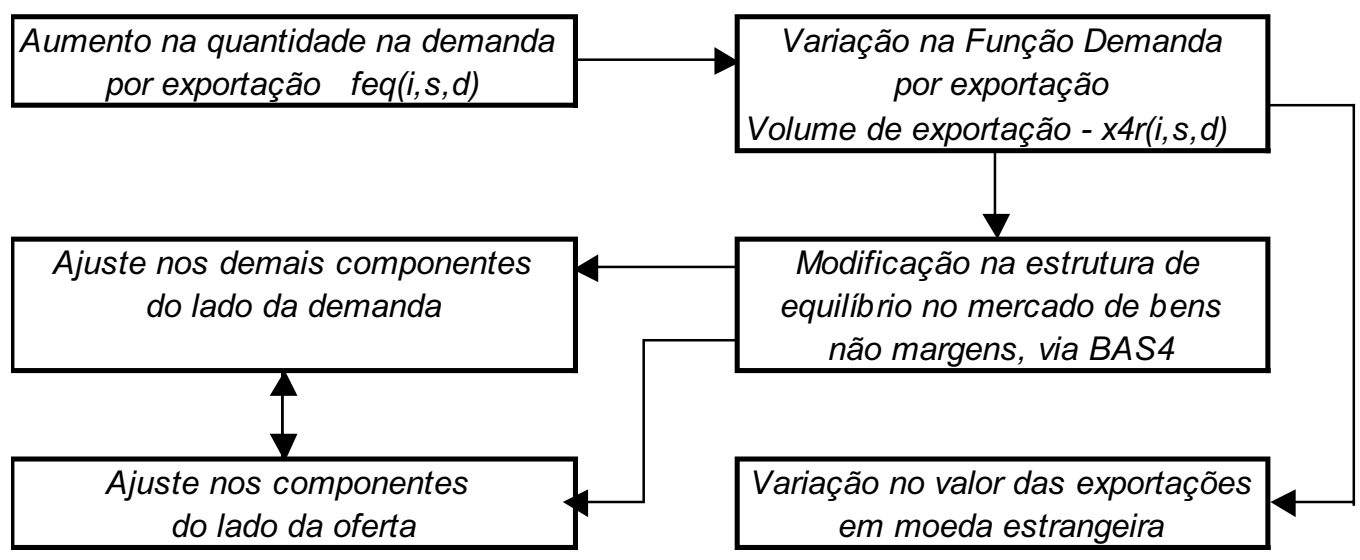




\subsection{Principais Resultados}

\section{- Análise do Ambiente Macroeconômico}

A primeira etapa da análise de resultados é realizada sobre algumas variáveis macroeconômicas escolhidas. Tal análise objetiva fornecer uma visão dos impactos do deslocamento da curva de demanda por exportação, para os cinco blocos de comércio, sobre a economia brasileira como um todo.

TABELA 2 - BRASIL: EFEITOS DE CURTO PRAZO EM VARIÁVEIS MACROECONÔMICAS SELECIONADAS

\begin{tabular}{lccccc}
\hline Variáveis & \multicolumn{5}{c}{ Expansão das exportações industriais para: } \\
\cline { 2 - 6 } & Mercosul & $\begin{array}{c}\text { União } \\
\text { Européia }\end{array}$ & NAFTA & $\begin{array}{c}\text { Resto da } \\
\text { Alca }\end{array}$ & $\begin{array}{c}\text { Resto do } \\
\text { Mundo }\end{array}$ \\
\hline PIB real (var \%) & 0.0019 & 0.0029 & 0.0025 & 0.0009 & 0.0031 \\
Consumo real das famílias (var \%) & 0.0036 & 0.0057 & 0.0048 & 0.0017 & 0.0062 \\
Volume de exportação (var \%) & 0.1380 & 0.2418 & 0.1972 & 0.0642 & 0.2644 \\
Volume de importação (var \%) & 0.0704 & 0.1142 & 0.0970 & 0.0332 & 0.1253 \\
\hline & \multicolumn{5}{c}{ Expansão das exportações agropecuárias para: } \\
\cline { 2 - 6 } & Mercosul & União & NAFTA & Resto da & Resto do \\
& 0.0000 & 0.0002 & 0.0000 & 0.0000 & 0.0000 \\
\hline PIB real (var \%) & 0.0001 & 0.0016 & 0.0002 & 0.0000 & 0.0004 \\
Consumo real das famílias (var \%) & 0.0016 & 0.0289 & 0.0070 & 0.0008 & 0.0061 \\
Volume de exportação (var \%) & 0.0010 & 0.0184 & 0.0035 & 0.0005 & 0.0042 \\
Volume de importação (var \%) & \multicolumn{5}{c}{ Mundo } \\
\hline
\end{tabular}

Fonte: A partir dos resultados do modelo.

Percebe-se que, no curto prazo, quando ocorre o deslocamento da curva de demanda por exportações do setor industrial há um crescimento do PIB real para todas as simulações. Entretanto, vale salientar que os melhores resultados para o PIB real ocorrem nas simulações com o resto do mundo (0.031\%), União Européia (0.029\%) e Nafta (0.025\%). O modelo B-MARIA27-IT especifica o consumo das famílias como função da renda disponível. O consumo real da economia apresenta variação positiva para todas as simulações. Os melhores resultados são resto do mundo $(0.062 \%)$, União Européia $(0.057 \%)$ e Nafta $(0.048 \%)^{7}-$ Tabela 2 .

7 É importante notar que a expansão de $1 \%$ tem magnitudes diferentes, dependendo do bloco, ou seja, dependendo da base de comparação (volume inicial de exportação). Por exemplo, $1 \%$ de exportações industriais para o Mercosul pode ser bem maior do que para o resto da Alça. 
A Tabela 2 apresenta ainda os resultados para as variáveis macroeconômicas, quando ocorre um deslocamento da curva de demanda por exportações do setor agropecuário. O impacto de tal deslocamento sobre o PIB é bem menor do que quando ocorre deslocamento da curva de demanda por exportação do setor industrial.

\section{- Comportamento dos Ajustes Internos às Economias Estaduais: Exportações Inter-regionais}

Como demonstrado na Figura 1, um dos impactos da variação na demanda por exportações $\left(f q_{(i s)}^{(4) r}\right)$ ocorre sobre a estrutura de equilíbrio dos bens não margens. $\mathrm{O}$ fluxograma explicita que o ajuste pode acontecer tanto pelo lado da demanda como pelo lado da oferta. Logo, esses ajustes podem ser captados por meio da análise do consumo intermediário (fluxo de comércio intra-regional e inter-regional), investimento, consumo das famílias e consumo dos governos regional e federal. Neste trabalho enfatiza-se o ajuste no componente dos fluxos de comércio intra e inter-regional, a fim de captar o impacto, sobre a dinâmica espacial da economia brasileira, das simulações de fortalecimento das interaçôes das unidades da Federação com o setor externo (e.g ótica do destino - exportaçôes). Em outras palavras, procura-se captar os benefícios das exportações internacionais sobre o comportamento das exportações estaduais.

Para tal, apresentam-se os resultados das exportações inter-regionais (Tabela 3) e os resultados de sua decomposição espacial ${ }^{8}$ (Figuras 2 a 6 e Tabelas 4 a 6). (Harrison et al., 1999). Tais resultados possibilitam mensurar a influência de cada Estado e macrorregião sobre as exportações das demais. Em outras palavras, é possível identificar um padrão de inter-relações entre os Estados e regiões a partir de um aumento do comércio internacional (i.e exportações internacionais) por blocos de comércio.

TABELA 3 - EFEITOS DE CURTO PRAZO SOBRE AS EXPORTAÇÕES INTERREGIONAIS (\%)

\begin{tabular}{|c|c|c|c|c|c|c|c|}
\hline & & & \multicolumn{3}{|c|}{$\begin{array}{l}\text { Expansão das exportações } \\
\text { industriais }\left(f q_{(i s)}^{(4) r}\right) \text { para: }\end{array}$} & \multicolumn{2}{|c|}{$\begin{array}{l}\text { Expansão das exportações } \\
\text { agropecuárias }\left(f q_{(i s)}^{(4) r}\right) \text { para: }\end{array}$} \\
\hline & & & Mercosul & União Européia & NAFTA & Mercosul & União Européia \\
\hline \multirow{5}{*}{ 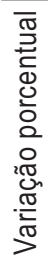 } & \multirow{5}{*}{ 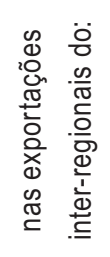 } & Norte & 0,0041 & 0,0063 & 0,0190 & 0,0001 & 0,0014 \\
\hline & & Nordeste & 0,0069 & 0,0116 & 0,0335 & 0,0002 & 0,0026 \\
\hline & & Sudeste & 0,0407 & 0,0706 & 0,1999 & 0,0009 & 0,0153 \\
\hline & & Sul & 0,0155 & 0,0252 & 0,0732 & 0,0004 & 0,0070 \\
\hline & & Centro-Oeste & 0,0058 & 0,0093 & 0,0281 & 0,0002 & 0,0029 \\
\hline
\end{tabular}

Fonte: A partir dos resultados do modelo.

8 A decomposição espacial (i.e dos subtotais) está formalmente apresentada no apêndice. 
Por meio da decomposição espacial é possível verificar, por exemplo, qual a contribuição das demais unidades da Federação para o resultado global dos fluxos inter-regionais de uma região ou Estado específico (e.g. Sudeste ou São Paulo). Na simulação de deslocamento da curva de demanda por exportação do setor industrial para o Mercosul a variação das exportações inter-regionais da região Sudeste foi de 0.0407. A decomposição proposta por Harrison et al., (1999), e implementada neste trabalho, permite verificar que o Estado de São Paulo contribui com 54,89\% desta variação, o Rio Grande do Sul contribui com 12,66\% e Minas Gerais com 7,05\%. Em outras palavras, os resultados da decomposição podem ser tomados como uma "proxy" dos vazamentos (i.e ligações) para as demais regiões.

Neste trabalho, apresenta-se a contribuição por macrorregião. Os resultados das simulações mostram que para todas as macrorregióes houve variação positiva nas exportações inter-regionais (Tabela 3).

As Figuras 2 a 6 mostram a distribuição espacial da contribuição média de cada unidade da Federação para o comércio inter-regional de cada uma das cinco macrorregiões brasileiras para cada um dos choques implementados neste trabalho. Portanto, na Figura 2A, por exemplo, os Estados representados pela cor branca (i.e Estados localizados na região Norte, Centro-Oeste, Nordeste, com exceção da Bahia e Sudeste, exceção Minas Gerais e São Paulo) contribuem com valores abaixo da média ${ }^{9}$ para a variação positiva das exportaçóes internas da região Norte. Por outro lado, os Estados representados pelas cores preta, cinza escuro e cinza contribuem com valores acima da média ${ }^{10}$ para a variação positiva das exportações internas da região Norte, ou seja, são as unidades que mais contribuem para o resultado positivo da variação do comércio inter-regional da macrorregião Norte. ${ }^{11}$ Cabe, portanto, salientar que os mapas foram construídos para representar desvios em relação à média.

Para a simulação de deslocamento da curva de demanda por exportações do setor industrial para o Mercosul percebe-se claramente a importância do Estado de São Paulo para os fluxos inter-regionais de todas as macrorregióes (a contribuição dos fluxos em direção a São Paulo é maior do que 50\% para todas as 27 unidades da Federação, inclusive os fluxos intra-regionais - i.e dentro do Estado) (Figura 2A a 2E e Tabela 4). Além disso, verifica-se que os demais Estados que apresentam resultados acima da média localizam-se nas macrorregióes Nordeste (Bahia), Sudeste (Minas Gerais) e Sul (Paraná, Santa Catarina e Rio Grande do Sul).

9 Desvios padrão abaixo da contribuição média.

10 Desvios padrão acima da contribuição média.

11 O mesmo raciocínio se aplica para as demais macrorregiões, ou seja, unidades da Federação representadas pela cor branca significam desvios padrões abaixo da contribuição média e unidades da Federação representadas pelas cores cinza, cinza escuro, preta significam desvios padrões acima da contribuição média. 
A distribuição espacial da variação positiva dos fluxos inter-regionais, para a simulação do setor industrial para o Mercosul, pode ser exposta da seguinte forma: a) na região Norte (Figura 2A) os fluxos inter-regionais são muito incipientes, ou seja, a contribuição dos demais Estados da região para o total das exportaçóes inter-regionais da própria região situa-se abaixo de $1 \%$ (i.e Estados em cor branca); b) na região Nordeste (Figura 2B) os fluxos inter-regionais também são muito incipientes para as unidades da Federação pertencentes à macrorregião, com exceção da Bahia; c) na região Sudeste (Figura 2C), além de São Paulo, vale a pena destacar a contribuição de Minas Gerais; d) a contribuição dos Estados do Paraná e Rio Grande do Sul (Figura 2D) para a variação do comércio inter-regional dos Estados da própria região situa-se acima dos 5\%; e) a região Centro-Oeste (Figura 2E) apresenta o mesmo padrão da região Norte, isto é, a contribuição dos Estados da própria macrorregião é ainda muito pequena (abaixo de $0,3 \%$ e e f) no cenário nacional, além de São Paulo, vale salientar a contribuição do Rio Grande do Sul (entre 12\% e 13\%), Minas Gerais (entre 7\% e 8\%), Paraná (entre 5 e 6\%), Santa Catarina (em torno dos 5\%) e Bahia (entre 4\% e 5\%).

Cabe ressaltar que o resultado das interações entre os Estados na sua forma intra e inter-regional depende, em um determinado grau, da estrutura produtiva dos Estados e macrorregiões, da localização, do perfil exportador, dentre outros. Assim sendo, a importância de Estados como São Paulo, Minas Gerais e Rio Grande do Sul, tanto no contexto intra-regional como no contexto inter-regional, pode ser em parte explicada pelo perfil industrial dos mesmos. Segundo dados da produção industrial para o ano de 1999, apresentados por Diniz (2002), os Estados anteriormente mencionados eram responsáveis por $48,0 \%, 9,4 \%$ e $8,5 \%$, respectivamente, da produção industrial. Assim sendo, ao variar as exportaçóes internacionais industriais dos Estados que pertencem a qualquer macrorregião é bem provável que a maior demanda por insumos necessários à produção dos Estados e regióes que tiveram o aumento na produção devido à variação nas exportações recaia sobre São Paulo, Minas Gerais e Rio Grande do Sul. 
FIGURA 2 - CONTRIBUIÇÃO ESTADUAL PARA A VARIAÇÃO DAS EXPORTAÇÕES REGIONAIS: SIMULAÇÃO MERCOSUL (INDÚSTRIA) - DESVIO PADRÃO

A) Norte

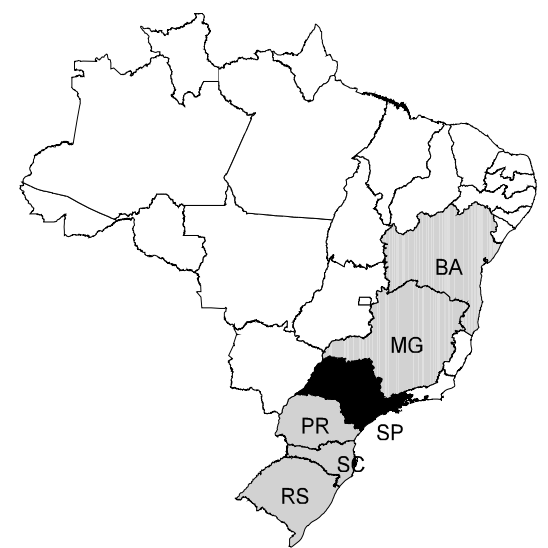

C) Sudeste

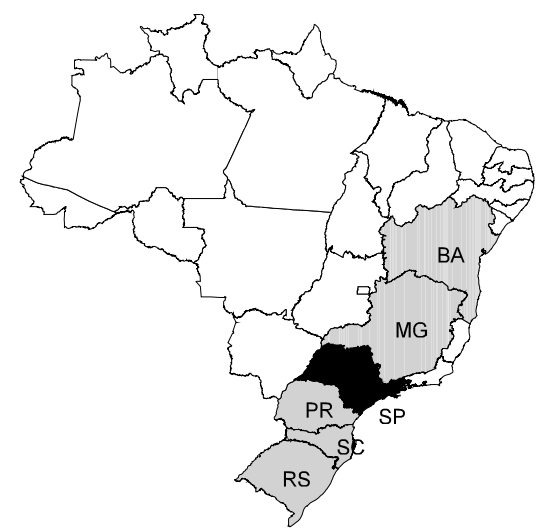

E) Centro-Oeste

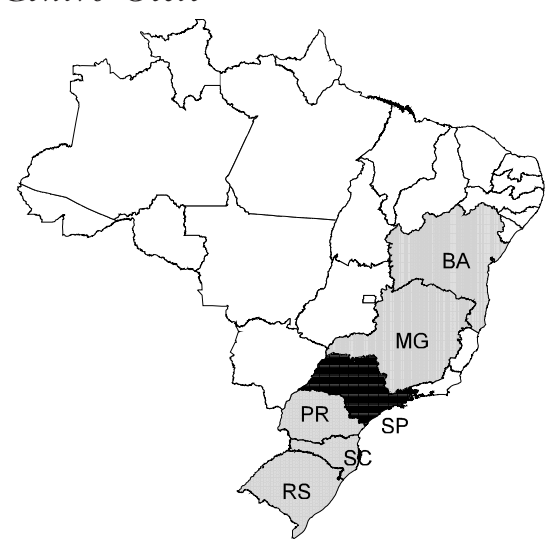

Estud. econ., São Paulo, 36(4): 833-866, out-dez 2006
B) Nordeste

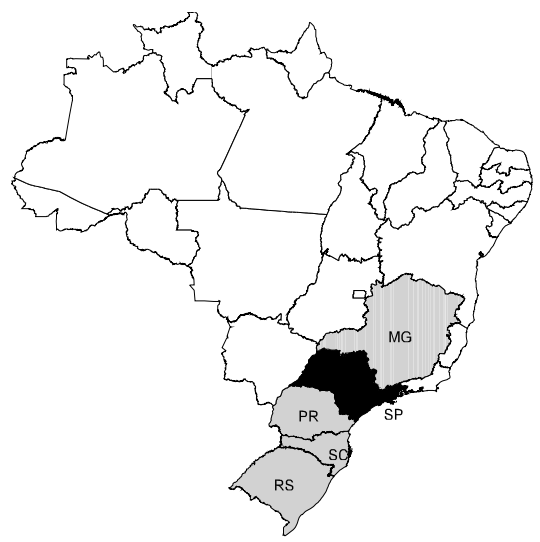

D) Sul

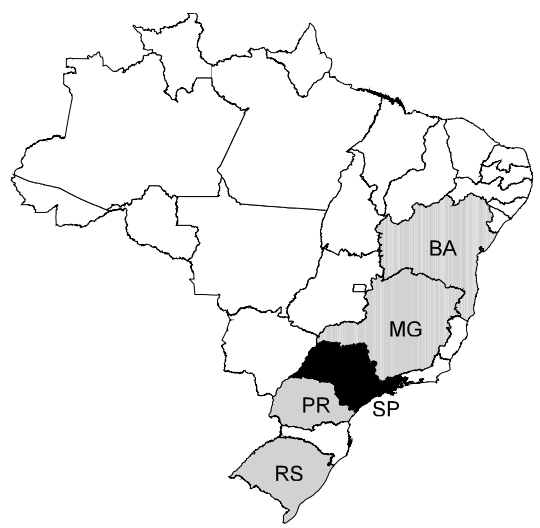


A Figura 3 mostra a distribuição espacial da variação positiva dos fluxos inter-regionais (e.g exportações inter-regionais) (Tabela 3) para a simulação de deslocamento da curva de demanda por exportações do setor industrial para a União Européia. Como visto na Tabela 3 , há uma variação positiva das exportações regionais para todas as unidades da Federação nessa simulação. Os mapas mostram a distribuição espacial desse resultado: a) São Paulo também apresenta uma importância nacional, ou seja, é a unidade da Federação com maior valor acima da média (é o Estado que mais contribui para o resultado do comércio inter-regional dos demais Estados - entre 24\% e 28\%); b) Minas Gerais, Paraná e Rio Grande do Sul têm posição de destaque nos fluxos das regiões Norte (Figura 3A), Nordeste (Figura 3B), Sudeste (Figura 3C) e Centro-Oeste (Figura $3 \mathrm{E}$ ); c) há um pequeno espraiamento dos resultados, que pode ser percebido pela inclusão do Estado do Pará nos Estados com resultados acima da média e pela inclusão do Estado do Mato Grosso (Tabela 4).

FIGURA 3 - CONTRIBUIÇÃO ESTADUAL PARA A VARIAÇÃO DAS EXPORTAÇÕES REGIONAIS: SIMULAÇÃO UNIÃO EUROPÉIA (INDÚSTRIA) - DESVIO PADRÃO

A) Norte

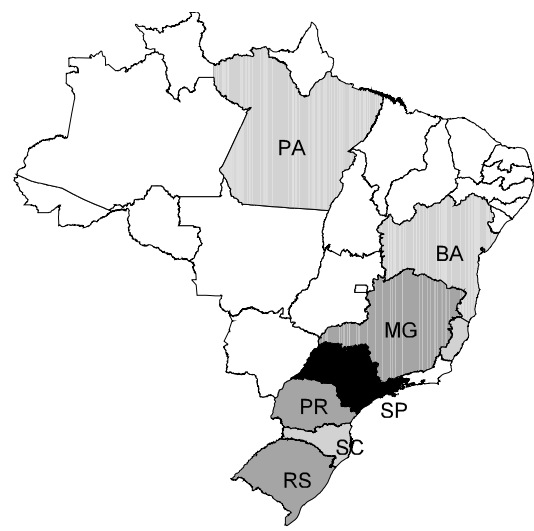

C) Sudeste

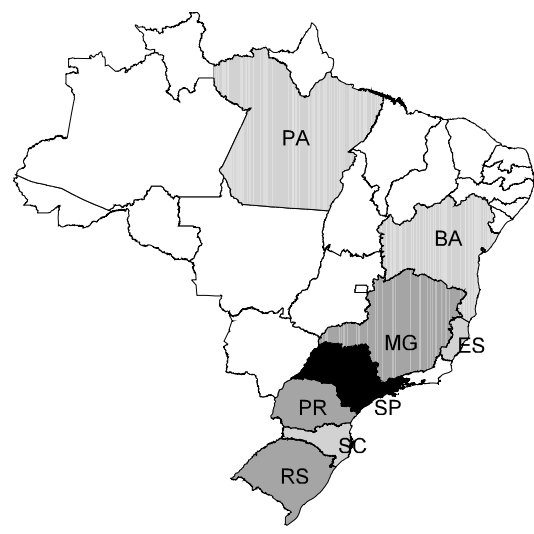

\section{B) Nordeste}

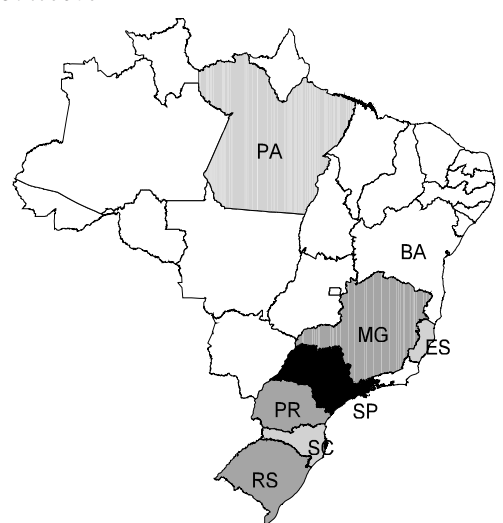

D) Sul

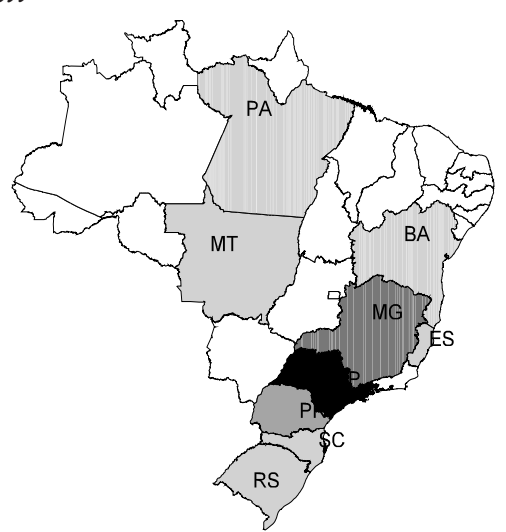




\section{E) Centro-Oeste}

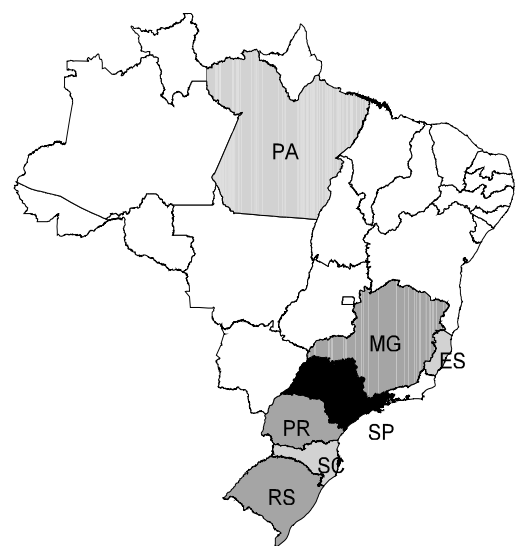

TABELA 4 - CONTRIBUIÇÃO DAS UNIDADES DA FEDERAÇÃO PARA A VARIAÇÃO DAS EXPORTAÇÕES MACRORREGIONAIS: SIMULAÇÕES DO SETOR INDUSTRIAL (MERCOSUL E UNIÃO EUROPÉIA)

\begin{tabular}{|c|c|c|c|c|c|c|c|c|c|c|}
\hline & Norte & Nordeste & Sudeste & Sul & $\begin{array}{l}\text { Centro- } \\
\text { Oeste }\end{array}$ & Norte & Nordeste & Sudeste & Sul & $\begin{array}{c}\text { Centro- } \\
\text { Oeste }\end{array}$ \\
\hline & 0.0041 & 0.0069 & 0.0407 & 0.0155 & 0.0058 & 0.0063 & 0.0116 & 0.0706 & 0.0252 & 0.0093 \\
\hline$A C$ & 0.00 & 0.00 & 0.00 & 0.00 & 0.00 & 0.00 & 0.00 & 0.00 & 0.00 & 0.00 \\
\hline AP & 0.01 & 0.01 & 0.01 & 0.01 & 0.01 & 0.09 & 0.15 & 0.15 & 0.16 & 0.14 \\
\hline AM & -0.63 & 0.49 & 0.49 & 0.52 & 0.48 & -0.24 & 0.17 & 0.17 & 0.19 & 0.17 \\
\hline PA & 0.22 & 0.42 & 0.41 & 0.40 & 0.36 & 5.80 & 9.56 & 9.16 & 9.29 & 8.34 \\
\hline RO & 0.00 & 0.02 & 0.02 & 0.03 & 0.03 & 0.00 & 0.00 & 0.00 & 0.00 & 0.00 \\
\hline $\mathrm{RR}$ & 0.00 & 0.00 & 0.00 & 0.00 & 0.00 & 0.00 & 0.00 & 0.00 & 0.00 & 0.00 \\
\hline TO & 0.00 & 0.00 & 0.00 & 0.00 & 0.00 & 0.00 & 0.00 & 0.00 & 0.00 & 0.00 \\
\hline $\mathrm{AL}$ & 0.09 & 0.09 & 0.11 & 0.10 & 0.09 & 0.14 & 0.13 & 0.15 & 0.15 & 0.13 \\
\hline BA & 4.95 & 3.26 & 5.26 & 5.21 & 4.60 & 3.99 & 2.51 & 3.98 & 4.08 & 3.64 \\
\hline CE & 0.74 & 0.56 & 0.77 & 0.77 & 0.67 & 0.28 & 0.20 & 0.28 & 0.28 & 0.25 \\
\hline MA & 0.54 & 0.49 & 0.61 & 0.60 & 0.52 & 0.95 & 0.82 & 1.01 & 1.03 & 0.91 \\
\hline PB & 0.05 & 0.02 & 0.05 & 0.05 & 0.05 & 0.31 & 0.16 & 0.33 & 0.34 & 0.29 \\
\hline PE & 0.66 & 0.49 & 0.75 & 0.73 & 0.63 & 0.52 & 0.37 & 0.56 & 0.56 & 0.49 \\
\hline $\mathrm{PI}$ & 0.01 & 0.01 & 0.01 & 0.01 & 0.01 & 0.23 & 0.20 & 0.24 & 0.24 & 0.21 \\
\hline RN & 0.06 & 0.05 & 0.06 & 0.06 & 0.06 & 0.13 & 0.12 & 0.14 & 0.14 & 0.13 \\
\hline SE & 0.23 & 0.12 & 0.25 & 0.25 & 0.22 & 0.27 & 0.14 & 0.28 & 0.29 & 0.26 \\
\hline ES & 1.55 & 1.64 & 1.47 & 1.71 & 1.59 & 4.79 & 4.88 & 4.36 & 5.17 & 4.85 \\
\hline$M G$ & 7.48 & 7.75 & 7.38 & 8.24 & 7.59 & 15.62 & 15.49 & 14.61 & 16.74 & 15.56 \\
\hline RJ & 3.25 & 3.40 & 3.28 & 3.60 & 3.42 & 1.33 & 1.33 & 1.27 & 1.43 & 1.38 \\
\hline SP & 56.18 & 55.86 & 52.64 & 58.94 & 54.75 & 28.01 & 26.65 & 24.61 & 28.57 & 26.78 \\
\hline PR & 6.26 & 6.48 & 6.77 & 5.43 & 6.68 & 13.29 & 13.19 & 13.54 & 11.33 & 13.94 \\
\hline SC & 5.11 & 5.34 & 5.53 & 3.52 & 5.38 & 7.41 & 7.42 & 7.56 & 5.00 & 7.67 \\
\hline RS & 12.24 & 12.46 & 12.95 & 8.58 & 12.26 & 10.44 & 10.18 & 10.40 & 6.99 & 10.27 \\
\hline DF & 0.00 & 0.00 & 0.00 & 0.00 & 0.00 & 0.00 & 0.00 & 0.00 & 0.00 & 0.00 \\
\hline GO & 0.33 & 0.35 & 0.41 & 0.40 & 0.24 & 1.99 & 2.01 & 2.32 & 2.37 & 1.41 \\
\hline MT & 0.02 & 0.02 & 0.02 & 0.02 & 0.01 & 3.18 & 2.89 & 3.31 & 3.92 & 2.39 \\
\hline MS & 0.66 & 0.65 & 0.75 & 0.79 & 0.36 & 1.47 & 1.40 & 1.57 & 1.72 & 0.80 \\
\hline
\end{tabular}


TABELA 5 - CONTRIBUIÇÃO DAS UNIDADES DA FEDERAÇÃO PARA A VARIAÇÃO DAS EXPORTAÇÕES MACRORREGIONAIS: SIMULAÇÕES DO SETOR INDUSTRIAL (NAFTA)

\begin{tabular}{|c|c|c|c|c|c|}
\hline & Norte & Nordeste & Sudeste & Sul & Centro-Oeste \\
\hline & 0.0190 & 0.0335 & 0.1999 & 0.0732 & 0.0281 \\
\hline$A C$ & 0.00 & 0.01 & 0.01 & 0.01 & 0.01 \\
\hline AP & 0.03 & 0.06 & 0.06 & 0.06 & 0.05 \\
\hline AM & -0.46 & 0.35 & 0.34 & 0.37 & 0.33 \\
\hline PA & 2.61 & 4.65 & 4.50 & 4.49 & 3.97 \\
\hline RO & 0.01 & 0.06 & 0.06 & 0.07 & 0.07 \\
\hline $\mathrm{RR}$ & 0.00 & 0.01 & 0.01 & 0.01 & 0.01 \\
\hline TO & 0.00 & 0.00 & 0.00 & 0.00 & 0.00 \\
\hline $\mathrm{AL}$ & 0.88 & 0.91 & 0.96 & 0.96 & 0.81 \\
\hline BA & 5.64 & 3.64 & 5.81 & 5.87 & 5.14 \\
\hline CE & 0.72 & 0.53 & 0.73 & 0.74 & 0.64 \\
\hline MA & 0.81 & 0.72 & 0.89 & 0.89 & 0.77 \\
\hline PB & 0.22 & 0.11 & 0.24 & 0.24 & 0.20 \\
\hline PE & 0.85 & 0.61 & 0.95 & 0.94 & 0.81 \\
\hline $\mathrm{PI}$ & 0.15 & 0.14 & 0.16 & 0.16 & 0.14 \\
\hline RN & 0.18 & 0.16 & 0.19 & 0.20 & 0.17 \\
\hline SE & 0.09 & 0.05 & 0.10 & 0.10 & 0.09 \\
\hline ES & 7.32 & 7.62 & 6.92 & 8.05 & 7.41 \\
\hline$M G$ & 13.99 & 14.19 & 13.49 & 15.28 & 13.95 \\
\hline RJ & 2.90 & 2.97 & 2.85 & 3.18 & 3.00 \\
\hline SP & 37.18 & 36.21 & 33.79 & 38.63 & 35.61 \\
\hline PR & 3.82 & 3.88 & 4.02 & 3.26 & 4.01 \\
\hline SC & 4.76 & 4.87 & 5.01 & 3.22 & 4.93 \\
\hline RS & 17.74 & 17.70 & 18.26 & 12.59 & 17.47 \\
\hline DF & 0.00 & 0.00 & 0.00 & 0.00 & 0.00 \\
\hline GO & 0.41 & 0.42 & 0.49 & 0.50 & 0.29 \\
\hline MT & 0.16 & 0.15 & 0.17 & 0.20 & 0.12 \\
\hline MS & 0.01 & 0.01 & 0.01 & 0.01 & 0.00 \\
\hline
\end{tabular}

A distribuição espacial dos resultados da simulação de deslocamento da curva de demanda por exportaçôes do setor industrial para o Nafta é semelhante aos resultados encontrados na simulação com a União Européia. Cabe destacar, em primeiro lugar, que os Estados de São Paulo, Minas Gerais e Rio Grande do Sul são os que mais contribuem para a variação positiva dos fluxos inter-regionais das cinco macrorregióes brasileiras (Figura 4A a 4E). Uma análise macrorregional mais detalhada permite afirmar que: a) no Nordeste a contribuição de todos os Estados da macrorregião, com exceção da Bahia, ainda é muito incipiente (Figura 4B); b) na região Sudeste destaca-se Minas Gerais com uma contribuição média entre 13\% e 15\%, e São Paulo, cuja contribuição média situa-se entre $36 \%$ e $38 \%$ para os fluxos dos demais Estados da macrorregião (Figura 4C); c) na região Sul (Figura 4D) é importante salientar o papel preponderante da economia gaúcha; d) na região Centro-Oeste (Figura 4E), 
os fluxos intra-regionais são muito incipientes (i.e representado pela cor branca), ou seja, a contribuição dos demais Estados da região para o total das exportações interregionais da região situa-se abaixo de 0,29\%;

As Figuras 5 e 6 apresentam a distribuição espacial dos resultados da simulação de deslocamento da curva de demanda por exportação do setor agropecuário para o Mercosul e União Européia, respectivamente. Os resultados indicam uma dinâmica um pouco diferente da apresentada para o setor industrial. Na simulação com o Mercosul podem ser destacados os seguintes resultados: a) aumento da contribuição do Mato Grosso e Mato Grosso do Sul para a variação positiva dos fluxos inter-regionais das macrorregiões brasileiras (Figuras 5A a 5E e Tabela 6); b) São Paulo e Paraná são as unidades da Federação que mais contribuem para o resultado positivo dos fluxos inter-regionais das cinco macrorregiões (Figuras 5A a 5E e Tabela 6); c) há uma concentração dos resultados acima da média na porção Centro-Sul do País; e d) na região Norte os fluxos intra-regionais são muito incipientes, isto é, a contribuição dos demais Estados da região para o total das exportações inter-regionais na região situa-se abaixo de 0,05\%(Figura 5A e Tabela 6);

Já na simulação com a União Européia verifica-se que: a) o Paraná é o Estado que mais contribui, no cenário nacional, para a variação dos fluxos inter-regionais dos demais Estados brasileiros (Tabela 6); b) o Estado do Mato Grosso ganha destaque no cenário nacional; c) ocorre perda de importância relativa do Estado de São Paulo no cenário nacional; e d) há uma concentração maior do que o Mercosul, pois um número menor de Estados apresenta contribuição acima da média.

As mudanças na distribuição espacial dos resultados das simulações de aumento das exportações agrícolas para o Mercosul e União Européia podem ser explicadas da seguinte maneira: segundo Diniz (2002), a distribuição porcentual da produção de grãos mostra uma concentração nesta atividade na região Centro-Sul do País. A participação porcentual está assim distribuída: a) região Sul: 48,3\%, b) região CentroOeste $24,1 \%$ e c) região Sudeste $15,8 \%$. Portanto, as interações mensuradas pelo modelo mostram um aumento de importância dos Estados localizados em tais regiões quando do exercício de simulação para o setor agrícola. Em outras palavras, a base produtiva agrícola dos Estados da macrorregião Centro-Sul é, em grande parte, responsável pelo aumento do comércio dos demais Estados com os Estados que compõem a macrorregião. Assim sendo, por meio dos resultados do modelo é possível verificar a importância de Estados como o Paraná e Mato Grosso do Sul no contexto intra-regional e inter-regional. 
FIGURA 4 - CONTRIBUIÇÃO ESTADUAL PARA A VARIAÇÃO DAS EXPORTAÇÕES REGIONAIS: SIMULAÇÃO NAFTA (INDÚSTRIA) DESVIO PADR ÃO

A) Norte

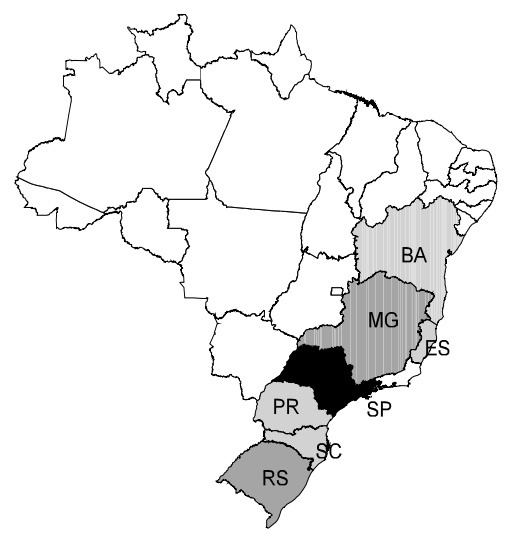

C) Sudeste

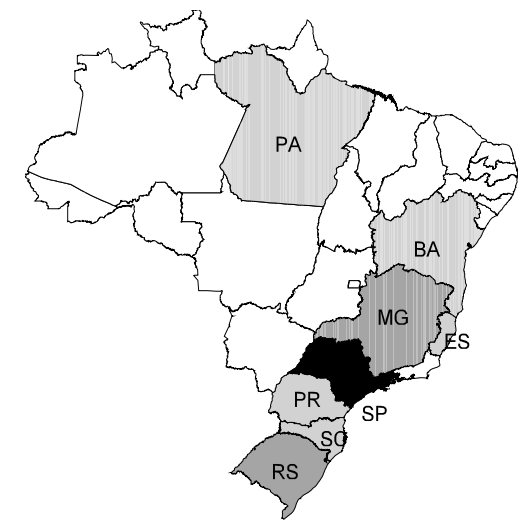

E) Centro-Oeste

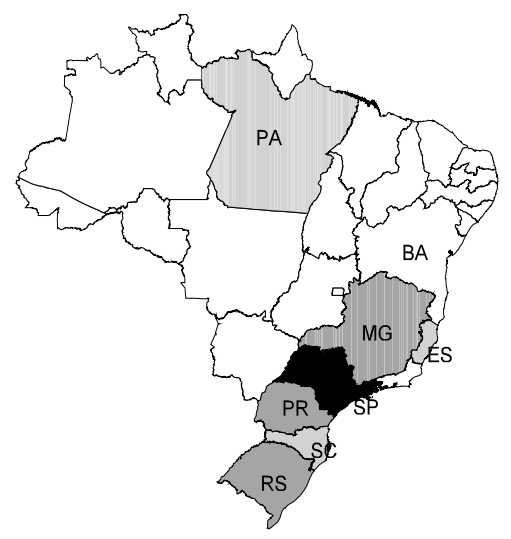

B) Nordeste

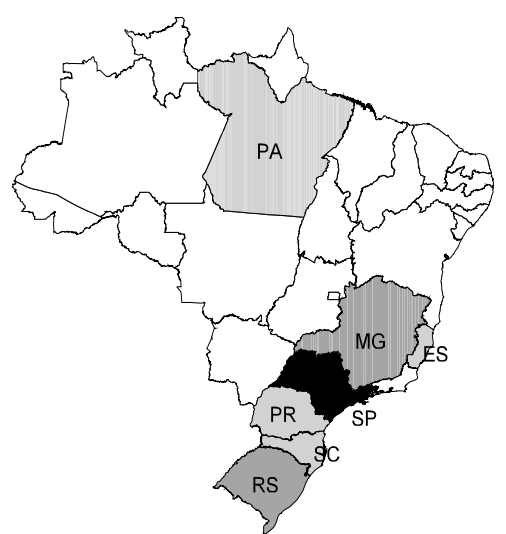

D) Sul

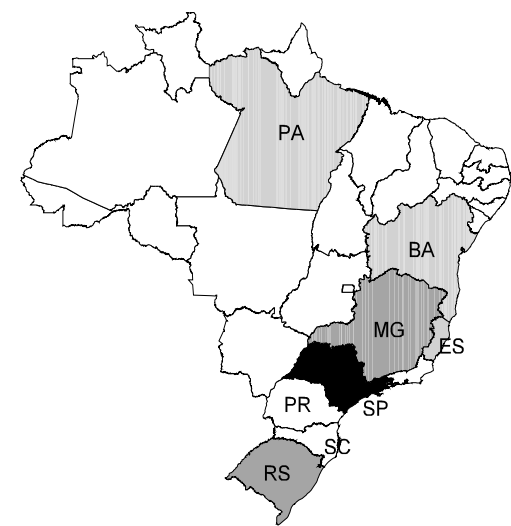


FIGURA 5 - CONTRIBUIÇÃO ESTADUAL PARA A VARIAÇÃO DAS EXPORTAÇÕES REGIONAIS: SIMULAÇÃO MERCOSUL (AGROPECUÁRIA) - DESVIO PADR ÃO

A) Norte

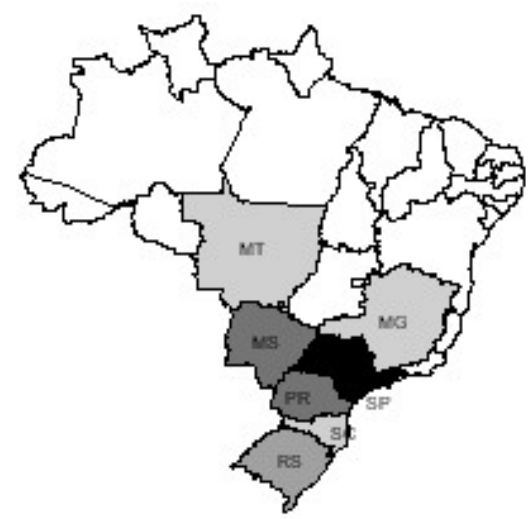

C) Sudeste

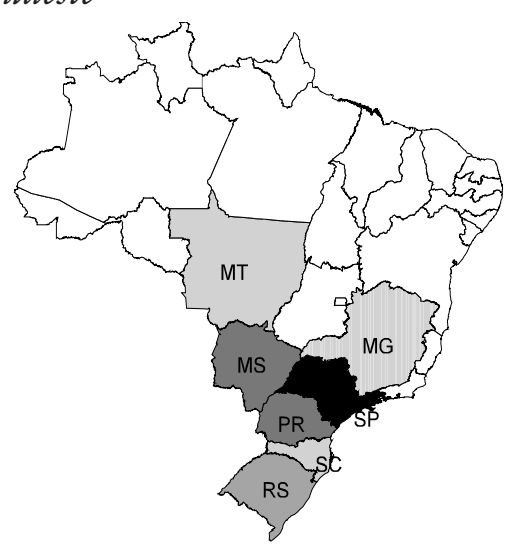

E) Centro-Oeste

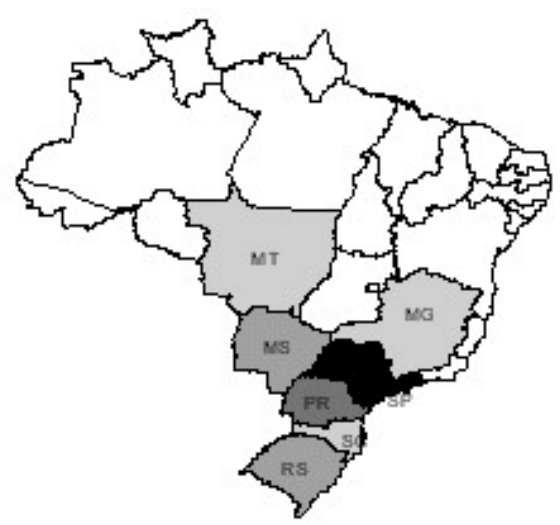

Estud. econ., São Paulo, 36(4): 833-866, out-dez 2006
B) Nordeste

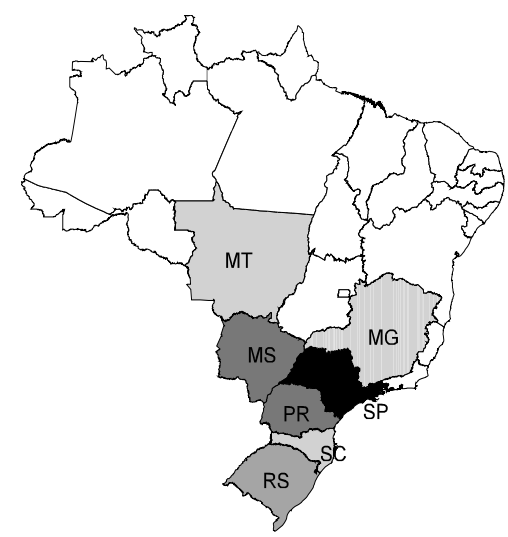

D) Sul

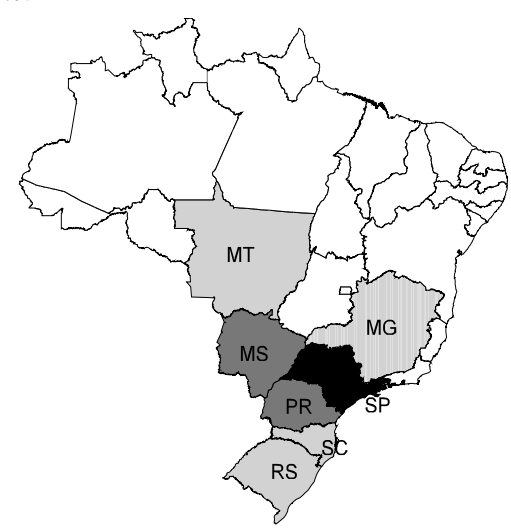


FIGURA 6 - CONTRIBUIÇÃO ESTADUAL PARA A VARIAÇÃO DAS EXPORTAÇÕES REGIONAIS: SIMULAÇÃO UNIÃO EUROPÉIA (AGROPECUÁRIA) - DESVIO PADR ÃO

A) Norte

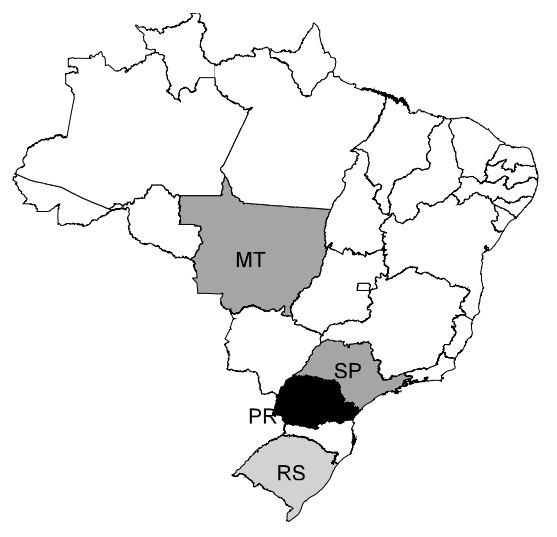

C) Sudeste

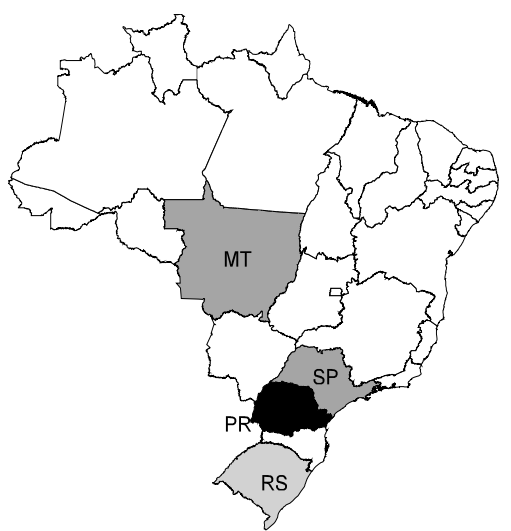

E) Centro-Oeste

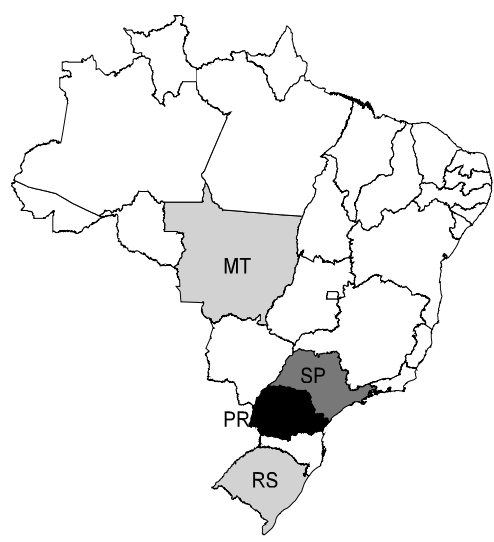

B) Nordeste

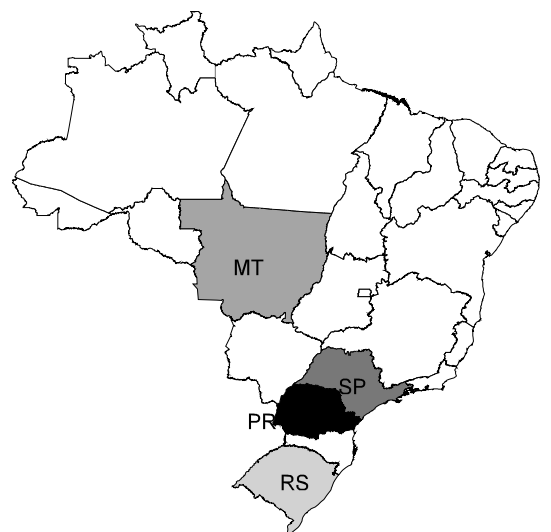

D) Sul

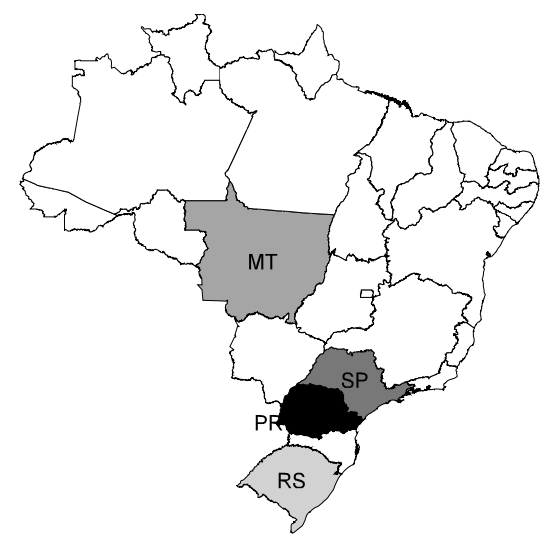


TABELA 6 - CONTRIBUIÇÃO DAS UNIDADES DA FEDERAÇÃO PARA A VARIAÇÃO DAS EXPORTAÇÕES MACRORREGIONAIS: SIMULAÇÕES DO SETOR AGROPECUÁRIO (MERCOSUL E UNIÃO EUROPÉIA)

\begin{tabular}{|c|c|c|c|c|c|c|c|c|c|c|}
\hline & Norte & Nordeste & Sudeste & Sul & $\begin{array}{l}\text { Centro- } \\
\text { Oeste }\end{array}$ & Norte & Nordeste & Sudeste & Sul & $\begin{array}{c}\text { Centro- } \\
\text { Oeste }\end{array}$ \\
\hline & 0.0001 & 0.0002 & 0.0009 & 0.0004 & 0.0002 & 0.0014 & 0.0026 & 0.0153 & 0.0070 & 0.0029 \\
\hline$A C$ & 0.00 & 0.00 & 0.00 & 0.00 & 0.00 & 0.00 & 0.01 & 0.01 & 0.01 & 0.01 \\
\hline AP & 0.00 & 0.00 & 0.00 & 0.00 & 0.00 & 0.00 & 0.00 & 0.00 & 0.00 & 0.00 \\
\hline AM & 0.02 & 0.06 & 0.06 & 0.06 & 0.05 & 0.16 & 0.22 & 0.21 & 0.23 & 0.23 \\
\hline PA & -0.01 & 0.00 & 0.00 & 0.00 & 0.00 & 0.08 & 0.77 & 0.76 & 0.83 & 0.84 \\
\hline RO & 0.00 & 0.00 & 0.00 & 0.00 & 0.00 & 0.00 & 0.00 & 0.00 & 0.00 & 0.00 \\
\hline $\mathrm{RR}$ & 0.00 & 0.00 & 0.00 & 0.00 & 0.00 & 0.00 & 0.00 & 0.00 & 0.00 & 0.00 \\
\hline TO & -0.01 & 0.00 & 0.00 & 0.00 & 0.00 & 0.00 & 0.07 & 0.06 & 0.07 & 0.07 \\
\hline $\mathrm{AL}$ & 0.00 & 0.00 & 0.00 & 0.00 & 0.00 & 0.00 & 0.00 & 0.00 & 0.00 & 0.00 \\
\hline $\mathrm{BA}$ & 2.16 & 1.37 & 2.16 & 2.29 & 2.39 & 2.30 & 1.45 & 2.28 & 2.43 & 2.47 \\
\hline CE & 2.22 & 1.54 & 2.47 & 2.54 & 2.74 & 1.64 & 1.14 & 1.79 & 1.87 & 1.98 \\
\hline MA & 0.00 & 0.00 & 0.00 & 0.00 & 0.00 & 3.31 & 2.52 & 3.41 & 3.50 & 3.59 \\
\hline PB & 0.08 & 0.07 & 0.13 & 0.12 & 0.11 & 0.06 & 0.04 & 0.06 & 0.06 & 0.07 \\
\hline PE & 0.06 & 0.04 & 0.06 & 0.06 & 0.05 & 1.42 & 0.85 & 1.44 & 1.50 & 1.54 \\
\hline $\mathrm{Pl}$ & 0.00 & 0.00 & 0.00 & 0.00 & 0.00 & 0.24 & 0.16 & 0.25 & 0.26 & 0.27 \\
\hline RN & 1.62 & 1.71 & 1.58 & 1.69 & 1.69 & 2.36 & 2.52 & 2.30 & 2.46 & 2.42 \\
\hline SE & 0.14 & 0.07 & 0.13 & 0.14 & 0.15 & 0.00 & 0.00 & 0.00 & 0.00 & 0.00 \\
\hline ES & 0.36 & 0.35 & 0.31 & 0.37 & 0.35 & 0.45 & 0.45 & 0.41 & 0.48 & 0.47 \\
\hline MG & 6.05 & 6.07 & 5.62 & 6.42 & 6.39 & 2.60 & 2.62 & 2.38 & 2.75 & 2.69 \\
\hline RJ & 0.02 & 0.04 & 0.06 & 0.06 & 0.05 & 0.13 & 0.13 & 0.12 & 0.14 & 0.13 \\
\hline SP & 23.89 & 24.33 & 23.82 & 25.75 & 26.04 & 19.99 & 20.50 & 19.74 & 21.54 & 21.36 \\
\hline PR & 19.91 & 20.17 & 20.04 & 18.10 & 21.29 & 39.16 & 39.85 & 38.89 & 35.87 & 40.85 \\
\hline SC & 5.19 & 5.33 & 5.29 & 4.64 & 5.65 & 3.28 & 3.37 & 3.30 & 2.90 & 3.48 \\
\hline RS & 11.11 & 11.12 & 10.88 & 9.72 & 12.22 & 4.27 & 4.31 & 4.14 & 3.72 & 4.60 \\
\hline DF & 0.00 & 0.00 & 0.00 & 0.00 & 0.00 & 1.18 & 1.22 & 1.28 & 1.28 & 1.26 \\
\hline GO & 0.71 & 0.68 & 0.64 & 0.71 & 0.35 & 1.81 & 1.80 & 1.66 & 1.86 & 0.93 \\
\hline MT & 9.40 & 9.61 & 9.42 & 9.87 & 6.39 & 12.35 & 12.71 & 12.27 & 12.97 & 8.63 \\
\hline MS & 17.02 & 17.48 & 17.34 & 17.50 & 14.11 & 3.20 & 3.31 & 3.22 & 3.28 & 2.09 \\
\hline
\end{tabular}

\section{CONSIDERAÇÕES FINAIS}

As análises anteriores fornecem importantes subsídios para o debate sobre a estrutura espacial dos fluxos de comércio no Brasil. A análise implementada neste trabalhou buscou mensurar a influência de cada Estado e macrorregião sobre as exportações dos demais Estados. Tal análise foi implementada por meio de um modelo de equilíbrio geral computável. Para identificar o padrão de interações entre as unidades da Federação foi feito um exercício de simulação que consistia na variação das exportações internacionais por setor (agricultura e indústria) e por destino (Mercosul, União Européia e Nafta). 
Assim sendo, pode-se entender a decomposição espacial da variação das exportações como uma proxy para medir a distribuição dos benefícios do setor exportador e os linkages entre as unidades da Federação. Os resultados mostram que:

1. Nas simulações com o setor industrial, as regióes Norte, Nordeste e Centro-Oeste apresentam uma estrutura de interações intra-regional muito incipiente, ou seja, a contribuição das demais unidades da Federação pertencentes a tais regiões se situa abaixo da média nacional.

2. Nas simulações com o setor industrial é possível perceber a importância das unidades da Federação localizadas no Sudeste, mais precisamente Minas Gerais e São Paulo, no Sul e o Estado da Bahia, tanto para os fluxos inter-regionais como intra-regionais. Portanto, o direcionamento dos fluxos de exportações regionais é na direção das regiões anteriormente mencionadas.

3. Na simulação do setor industrial com o Mercosul é possível divisar a grande influência de São Paulo para todas as macrorregiões. O Estado de São Paulo contribui com mais de $50 \%$ da variação porcentual das exportaçóes das demais unidades da Federação.

4. Na simulação do setor industrial com a União Européia é possível verificar um espraiamento nas exportações inter-regionais. Em outras palavras, há uma perda de importância relativa dos fluxos do Estado de São Paulo no contexto nacional, que passa a contribuir, em média, com $27 \%$ dos fluxos, e Estados como Minas Gerais, Paraná, Rio Grande do Sul têm a participação relativa aumentada no contexto nacional.

5. É também relevante ressaltar os resultados para o setor agropecuário. Na simulação com o Mercosul, a direção espacial dos linkages tem uma pequena modificação. São Paulo perde importância relativa e os Estados do Mato Grosso e Mato Grosso do Sul aumentam a sua contribuição na variação das exportações das demais unidades da Federação.

As contribuições que este trabalho oferece podem ser resumidas nos seguintes pontos: a) construção de um modelo interestadual de equilíbrio geral computável com detalhamento do setor externo, aumentando a discussão a respeito da utilização dessa metodologia em trabalhos para a economia brasileira; e b) identificação e análise da espacialidade dos fluxos de exportações internas à economia brasileira.

Como o presente trabalho focalizou as interações entre as unidades da Federação, com ênfase nas exportações, pôde-se mensurar e/ou identificar a distribuição dos 
benefícios, em termos espaciais, do setor exportador. Ademais, o mesmo pode ser desdobrado para examinar de forma completa questões inerentes ao comércio internacional. Portanto, uma possível extensão do presente estudo seria a incorporação de uma discussão global do comércio internacional (e.g exportações e importações) para verificar o seu impacto sobre os fluxos inter-regionais globais (e.g exportaçóes e importações). Esta extensão permitiria tratar com mais propriedade questões inerentes ao caráter concentracionista ou não das estratégias comerciais brasileiras.

\section{REFERENNCIAS BIBLIOGRÁFICAS}

CONFAZ. Balança comercial interestadual de 1997. Brasília: Ministério da Fazenda, 1997.

Dixon, P. B.; Parmenter, B. R.; Powell, A. A.; Wilcoxen, P. J. Notes and problems in applied general equilibrium economics. In: Bliss, C. J.; Intriligator, M. D. (Eds), Advanced textbooks in economics (v. 32). Amsterdam: Elsevier, 1992.

Dixon, P. B.; Parmenter, B. R.; Powell, Sutton, J.; Vincent, D. P. ORANI: a multisectoral model of the Australasian economy. North Holland, 1997.

Diniz, C. C. A nova configuração urbano-industrial no Brasil. In: Kon, A. (org.), Unidade e fragmentação: a questão regional no Brasil. São Paulo: Editora Perspectiva, 2002.

Domingues, E. P Dimensão regional e setorial da integração brasileira na área de livre comércio das Américas. 2002. Tese (Doutorado), apresentada ao IPE/USP, São Paulo.

Haddad, E. A. (coord.), B-MARIA-27: an insterstate CGE model for Brazil. Research memo, FIPE: São Paulo, SP, 2003.

Haddad, E. A.; Azzoni, C. R.; Domingues, E. P.; Perobelli, F. S. Contas estaduais e matriz interestadual de insumo-produto para o Brasil. Economia Aplicada, v. 6, n. 4, p. 875-895, out/dez. 2002.

Haddad, E. A.; Domingues, E. P; Perobelli, F. S. Regional effects of economic integration: the case of Brazil. Journal of Policy Modeling 24, p. 453-482, 2002.

Haddad, E. A.; Domingues, E. P. EFES - um modelo aplicado de equilíbrio geral para a economia brasileira: projeções setoriais para 1999-2004. Estudos Econômicos, v. 31, n. 1, p 89-125, jan/mar. 2001.

Haddad, E. A.; Hewings, G. J. D. Linkages and interdependence in the Brazilian economy: an evaluation of the interregional input-output system, 1985. Urbana: University of Illinois at Urbana-Champaign, Regional Economics Laboratory. Discussion Paper, 1998.

The theoretical specification of B-MARLA. Discussion Paper REAL 97-T-5, Regional Economics Applications Laboratory, University of Illinois at UrbanaChampaign, 1997. 
Haddad, E. A. Regional inequality and structural changes. Lessons from the Brazilian experience. Ashgate, 1999.

Harrison, W. J.; Horridge, J. M.; Pearson, K. R. Decomposing simulation results with respect to exogenous shocks. Preliminary Working Paper. N. IP-73. Centre of Policy Studies and Impact Project, 1999.

Harrison, W. J.; Pearson, K. R. Computing solutions for large general equilibrium models using GEMPACK. Preliminary Working Paper n. IP-64, IMPACT Project, Clayton: Monash University, 1994.

. An introduction to GEMPACK. GEMPACK user documentation GPD-1 (3rd ed). IMPACT Project and KPSOFT, September 1999.

Hulu, E. A.; Hewings, G. J. D. The development and use of interregional inputoutput models for Indonesia under conditions of limited information. Review of Economic Studies, 5, 1993.

IBGE. Contas nacionais do Brasil: 1985-2001. Rio de Janeiro: Fundação IBGE, 2001.

. Regionalização das transações do setor público. Rio de Janeiro: Fundação IBGE, 2000. 1997.

. Matriz de insumo-produto para o Brasil. Rio de Janeiro: Fundação IBGE,

MDIC - Ministério do Desenvolvimento Indústria e Comércio. Sistema Alice. Disponível em: http://aliceweb.desenvolvimento.gov.br/, 2001.

Miller, R. E.; Blair, P. D. Input-output analysis: foundations and extensions. New Jersey: Prentice Hall, 1985.

Perobelli, F. S. Análise espacial das interações econômicas entre os estados brasileiros. 2004. Tese (Doutorado), apresentada ao IPE/USP, São Paulo.

Perobelli, F. S.; Haddad, E. A. Brazilian interregional trade (1985-1996): an exploratory data analysis. In: Anais do XXXI Encontro Nacional de Economia (ANPEC). Porto Seguro, 2003a.

. Interdependence among the Brazilian states: an input-output approach. In: $50^{\text {th }}$ North American Meetings of the Regional Science Association International. Philadelphia, Pennsylvania. EUA, 2003 b.

Peter, M. W.; Horridge, M.; Meagher, G. A.; Naqvi, F.; Parmenter, B. R. The theoretical structure of MONASH-MRF. Preliminary working paper n. 85, COPS. Monash Universtity, April 1996.

Ramos, L. O. R. Matriz de insumo-produto Brasil. Brasília: IBGE. Série Relatórios Metodológicos, v. 18, 1997.

Shoven, J. B.; Whalley, J. Applying general equilibrium. Cambridge Universtity Press, 1992.

Todaro, M. Economic development. New York: Longman, 1994. 


\section{$A P \hat{E N D I C E}$}

As formas funcionais das principais equações do modelo de EGC interestadual são apresentadas neste apêndice, bem como a definição das principais variáveis, parâmetros e coeficientes.

Em relação à notação, letras maiúsculas são utilizadas para variáveis em níveis, e letras minúsculas para as taxas anuais de crescimento correspondentes (variação porcentual). Os sobrescritos $(u), u=0,1 j, 2 j, 3,4,5,6$, referem-se, respectivamente, à produção $(0)$ e aos seis tipos de usuários regionais dos produtos identificados no modelo: produtores no setor $j(1 j)$, investidores no setor $j(2 j)$, famílias (3), compradores de bens exportados (4), governo regional (5) e governo federal (6); o segundo sobrescrito identifica a região doméstica onde o usuário está localizado. Os insumos são identificados por dois subscritos: o primeiro assume os valores $1, \ldots, g$, para os bens, $g+1$, para os fatores primários, e $g+2$, para "outros custos" (basicamente impostos e subsídios sobre a produção); o segundo subscrito identifica a origem do insumo, seja ela doméstica b (1b) ou importada (2), ou proveniente do trabalho (1), capital (2) ou terra (3). O símbolo $(\bullet)$ é empregado para indicar a soma sobre um determinado índice.

\section{Equaçôes}

(Al) Substituição entre produtos de diferentes fontes regionais domésticas

$$
\begin{aligned}
& x_{(i(1 b))}^{(u) r}=x_{(i(1 \bullet))}^{(u) r}-\sigma_{(i)}^{(u) r}\left(p_{(i(1 b))}^{(u) r}-\sum_{l \in S^{*}}\left(V(i, 1 l,(u), r) / V(i, 1 \bullet,(u), r)\left(p_{(i(1)))}^{(u) r}\right)\right)\right. \\
& i=1, \ldots, g ; \quad b=1, \ldots, q ; \quad(u)=3 \text { e }(k j) \text { para } k=1 \text { e } 2 \text { e } j=1, \ldots, h ; r=1, \ldots, R
\end{aligned}
$$

(A2) Substituição entre bens domésticos e importados

$$
\begin{aligned}
& x_{(i s)}^{(u) r}=x_{(i \bullet)}^{(u) r}-\sigma_{(i)}^{(u) r}\left(p_{(i s)}^{(u) r}-\sum_{l=1 \bullet, 2}\left(V(i, l,(u), r) / V(i, \bullet,(u), r)\left(p_{(i l)}^{(u) r}\right)\right)\right. \\
& i=1, \ldots, g ; s=1 \bullet \text { e } 2 ; \quad(u)=3 \text { e }(k j) \text { para } k=1 \text { e } 2 \text { e } j=1, \ldots, h ; r=1, \ldots, R
\end{aligned}
$$

(A3) Substituição entre trabalho e capital

$$
\begin{aligned}
x_{(g+1, s)}^{(1 j) r}-a_{(g+1, s)}^{(1 j) r}=x_{(g+1 \bullet \bullet}^{(1 j) r} & -\sigma_{(g+1)}^{(1 j) r}\left\{p_{(g+1, s)}^{(1 j) r}+a_{(g+1, s)}^{(1 j) r}\right. \\
& \left.-\sum_{l=1,2,3}(V(g+1, l,(1 j), r) / V(g+1, \bullet,(1 j), r))\left(p_{(g+1, l}^{(1 j) r}+a_{(g+1, l)}^{(1 j) r}\right)\right\}
\end{aligned}
$$

$j=1, \ldots, h ; s=1,2$ e $3 ; r=1, \ldots, R$ 
(A4) Demanda por bens compostos intermediários, de investimento e fatores primários

$$
\begin{array}{rl}
x_{(i \bullet)}^{(u) r}=z^{(u) r}+a_{(i)}^{(u) r} & u=(k j) \text { para } k=1,2 \text { e j=1,..,h } \\
\text { se } & u=(1 j) \text { então } i=1, \ldots, g+2 \\
\text { se } u & =(2 j) \text { então } i=1, \ldots, g \\
r & =1, \ldots, R
\end{array}
$$

(A5) Demanda das famílias por bens compostos

$V(i, \bullet,(3), r)\left(p_{(i \bullet)}^{(3) r}+x_{(i \bullet)}^{(3) r}\right)=\gamma_{(i)}^{r} P_{(\bullet \bullet}^{(3) r} Q^{r}\left(p_{(i \bullet)}^{(3) r}+x_{(i \bullet)}^{(3) r}\right)+\beta_{(i)}^{r}\left(C^{r}-\sum_{j \in G} \gamma_{(j)}^{r} P_{(i \bullet)}^{(3) r} Q^{r}\left(p_{(i \bullet)}^{(3) r}+x_{(i \bullet)}^{(3) r}\right)\right)$

$i=1, \ldots, g ; r=1, \ldots, R$

(A6) Composição setorial da produção

$x_{(i 1)}^{(0 j) r}=z^{(1 j) r}+\sigma^{(0 j) r}\left(p_{(i 1)}^{(0) r}-\sum_{t \in G}(Y(t, j, r) / Y(\bullet, j, r)) p_{(t 1)}^{(0) r}\right)$

$j=1, \ldots, h ; \quad i=1, \ldots, g ; r=1, \ldots, R$

(A7) Impostos indiretos

$$
\begin{gathered}
t(\tau, i, s,(u) r)=f_{(\tau)}+f_{(\tau i)}+f_{(\tau i)}^{(u)}+f_{(\tau i)}^{(u) r}, \quad i=1, \ldots, g ; \quad s=1 b, 2 \text { para } b=1, \ldots, q ; \tau=1, \ldots, t \\
(u)=(3),(4),(5),(6) \text { e }(k j) \text { para } k=1,2 ; j=1, \ldots, h \\
r=1, \ldots, R
\end{gathered}
$$

(A8) Preços de compra relacionados aos preços básicos, margens (custos de transporte) e impostos

$$
\begin{aligned}
V(i, s,(u), r) p_{(i s)}^{(u) r} & =\left(B(i, s,(u), r)+\sum_{\tau \in T} T(\tau, i, s,(u), r)\right)\left(p_{(i s)}^{(0)}+t(\tau, i, s, u, r)\right)+\sum_{m \in G} M(m, i, s,(u), r) p_{(m 1)}^{(0) r}, \\
& i=1, \ldots, g ;(u)=(3),(4),(5),(6) \\
& e(k j) \text { para } k=1,2 \text { e } j=1, \ldots, h ; s=1 b, 2 \text { para } b=1, \ldots, q \\
& r=1, \ldots, R
\end{aligned}
$$


(A9) Demanda externa (exportações) por bens domésticos

$\left(x_{(i s)}^{(4) r}-f q_{(i s)}^{(4) r}\right)=\eta_{(i s)}^{r}\left(p_{(i s)}^{(4) r}-e-f p_{(i s)}^{(4) r}\right), \quad i=1, \ldots, g ; s=1 b, 2$ para $b=1, \ldots, q ; r=1, \ldots, R$

(A10) Demanda do governo regional

$x_{(i s)}^{(5) r}=x_{(\bullet)}^{(3) r}+f_{(i s)}^{(5) r}+f^{(5) r}+f^{(5)} \quad i=1, \ldots, g ; s=1 b, 2$ para $b=1, \ldots, q ; r=1, \ldots, R$

(A11) Demanda do governo federal

$x_{(i s)}^{(6) r}=x_{(\cdot)}^{(3) \cdot}+f_{(i s)}^{(6) r}+f^{(6) r}+f^{(6)} \quad i=1, \ldots, g ; s=1 b, 2$ para $b=1, \ldots, q ; r=1, \ldots, R$

(A12) Demanda por margens para bens domésticos

$$
\begin{gathered}
m, i=1, \ldots, g ; \\
(u)=(3),(4 b) \text { para } b=1, \ldots, r,(5) e \\
x_{(m 1)}^{(i s)(u) r}=x_{(i s)}^{(u) r}+a_{(m 1)}^{(i s)(u) r} \quad j=1, \ldots, h ; s=1 b, 2 \text { para } b=1, \ldots, r ; \\
r=1, \ldots, R
\end{gathered}
$$

(A13) Demanda iguala a oferta para bens domésticos regionais

$$
\begin{gathered}
\sum_{j \in H} Y(l, j, r) x_{(l 1)}^{(0 j) r}=\sum_{u \in U} B(l, 1,(u), r) x_{(l 1)}^{(u) r}+\sum_{i \in G} \sum_{s \in S} \sum_{u \in U} M(l, i, s,(u), r) x_{(l 1)}^{(i s)(u) r} \\
l=1, \ldots, g ; r=1, \ldots, R
\end{gathered}
$$

(A14) Receita regional iguala custo para os setores

$$
\sum_{l \in G} Y(l, j, r)\left(p_{(l 1)}^{(0) r}+a_{(l 1)}^{(0) r}\right)=\sum_{l \in G^{*}} \sum_{s \in S} V(l, s,(1 j), r)\left(p_{(l s)}^{(1 j) r}\right), \quad j=1, \ldots, h ; r=1, \ldots, R
$$

(A15) Preço básico dos bens importados

$$
p_{(i(2))}^{(0)}=p_{(i(2))}^{(w)}-e+t_{(i(2))}^{(0)}, \quad i=1, \ldots, g
$$

(A16) Custo de capital para as indústrias regionais

$$
V(\bullet, \bullet,(2 j), r)\left(p_{(k)}^{(1 j) r}-a_{(k)}^{(1 j) r}\right)=\sum_{i \in G} \sum_{s \in S} V(i, s,(2 j), r)\left(p_{(i s)}^{(2 j) r}+a_{(i s)}^{(2 j) r}\right), \quad j=1, \ldots, h ; r=1, \ldots, R
$$


(A17) Comportamento do investimento

$z^{(2 j) r}=x_{(g+1,2)}^{(1 j) r}+100 f_{(k)}^{(2 j) r}, \quad j=1, \ldots, h ; r=1, \ldots, R$

(A18) Estoque de capital para o período $\mathrm{T}+1$ - estática comparativa

$x_{(g+1,2)}^{(1 j) r}(1)=x_{(g+1,2)}^{(1 j) r} \quad j=1, \ldots, h ; r=1, \ldots, R$

(A19) Definição da taxa de retorno do capital

$r_{(j)}^{r}=Q_{(j)}^{r}\left(p_{(g+1,2)}^{(1 j) r}-p_{(k)}^{(1 j) r}\right), \quad j=1, \ldots, h ; r=1, \ldots, R$

(A20) Relação entre crescimento do capital e taxas de retorno

$r_{(j)}^{r}-\omega=\varepsilon_{(j)}^{r}\left(x_{(g+1,2)}^{(1 j) r}-x_{(g+1,2)}^{(\bullet) r}\right)+f_{(k)}^{r}, \quad j=1, \ldots, h ; r=1, \ldots, R$

Outras definições incluem: receitas dos impostos indiretos, volume de importação dos bens, componentes do PIB regional e nacional, índices de preços regionais e nacionais, determinação de salário, definição do preço dos fatores e emprego agregado.

Variáveis

\begin{tabular}{|c|c|c|}
\hline Variáveis & Índices & Descrição \\
\hline$x_{(i s)}^{(u) r}$ & $\begin{array}{l}(u)=(3),(4),(5),(6) \mathrm{e} \\
(k j) \text { para } k=1,2 \text { e } j=1, \ldots, h ; \\
\text { se }(u)=(1 \mathrm{j}) \text { então } i=1, \ldots, g+2 ; \\
\text { se }(u) \neq(1 \mathrm{j}) \text { então } \mathrm{i}=1, \ldots, g ; \\
s=1 b, 2 \text { para } b=1, \ldots, q ; \mathrm{e} \mathrm{i}=1, \ldots, g \\
\text { e } \\
\mathrm{s}=1,2,3 \text { para } i=g+1 \\
r=1, \ldots, R\end{array}$ & $\begin{array}{l}\text { Demanda do usuário }(u) \text { na região } r \text { pelo bem ou } \\
\text { fator primário (is) }\end{array}$ \\
\hline$p_{(i s)}^{(u) r}$ & $\begin{array}{l}(u)=(3),(4),(5),(6) \mathrm{e} \\
(k j) \text { para } k=1,2 \text { e } j=1, \ldots, h ; \\
\text { se }(u)=(1 j) \text { então } i=1, \ldots, g+2 ; \\
\text { se }(\mathrm{u}) \neq(1 j) \text { então } \mathrm{i}=1, \ldots, g ; \\
s=1 \mathrm{~b}, 2 \text { para } b=1, \ldots, q ; \text { e } i=1, \ldots, g \\
\text { e } \\
s=1,2,3 \text { para } i=g+1 \\
r=1, \ldots, R\end{array}$ & $\begin{array}{l}\text { Preço pago pelo usuário }(u) \text { na região } r \text { pelo bem } \\
\text { ou fator primário }(i s)\end{array}$ \\
\hline
\end{tabular}




\begin{tabular}{|c|c|c|}
\hline Variáveis & Índices & Descrição \\
\hline$x_{(i \bullet)}^{(u) r}$ & $\begin{array}{l}(u)=(3) \text { e }(k j) \text { para } k=1,2 \text { e } \\
j=1, \ldots, \text { h. } \\
\text { se }(u)=(1 j) \text { então } i=1, \ldots, g+1 ; \\
\text { se }(u) \neq(1 j) \text { então } i=1, \ldots, g \\
r=1, \ldots, R\end{array}$ & $\begin{array}{l}\text { Demanda pelo bem composto ou fator primário } i \\
\text { pelo usuário }(u) \text { ba região } r\end{array}$ \\
\hline$a_{(g+1, s)}^{(1 j) r}$ & $\begin{array}{l}j=1, \ldots, h \text { e } s=1,2,3 \\
r=1, \ldots, R\end{array}$ & $\begin{array}{l}\text { Mudança tecnológica: utilização de fatores primários } \\
\text { na região } r\end{array}$ \\
\hline$a_{(i)}^{(u) r}$ & $\begin{array}{l}i=1, \ldots, g,(u)=(3) \text { e }(k j) \text { para } k=1,2 \\
\text { e } j=1, \ldots, h \\
r=1, \ldots, R\end{array}$ & $\begin{array}{l}\text { Mudança tecnológica relacionada ao uso do bem i } \\
\text { pelo usuário }(u) \text { na região } r\end{array}$ \\
\hline$C^{r}$ & & Gasto total regional das famílias na região $r$ \\
\hline$Q^{r}$ & & Número de famílias \\
\hline$z^{(u) r}$ & $\begin{array}{l}(u)=(k j) \text { para } k=1,2 \text { e } j=1, \ldots, h \\
r=1, \ldots, R\end{array}$ & $\begin{array}{l}\text { Níveis de atividade: produção corrente e investi- } \\
\text { mento por indústria na região } r\end{array}$ \\
\hline$f q_{(i s)}^{(4) r}$ & $\begin{array}{l}i=1, \ldots, g ; s=1 b, 2 \text { para } b=1, \ldots, q \\
r=1, \ldots, R\end{array}$ & $\begin{array}{l}\text { Termo de deslocamento na curva de demanda por } \\
\text { exportações, para quantidades }\end{array}$ \\
\hline$f p_{(i s)}^{(4) r}$ & $\begin{array}{l}i=1, \ldots, g ; s=1 b, 2 \text { para } b=1, \ldots, q \\
r=1, \ldots, R\end{array}$ & $\begin{array}{l}\text { Termo de deslocamento na curva de demanda por } \\
\text { exportações, para preços }\end{array}$ \\
\hline$e$ & & Taxa de câmbio $R \$ / U S \$$ \\
\hline$x_{(m 1)}^{(i s)(u) r}$ & $\begin{array}{l}m, i=1, \ldots, g ; s=1 b, 2 \text { para } \mathrm{b}=1, \ldots, q \\
(u)=(3),(4),(5),(6) \mathrm{e} \\
(k j) \text { para } k=1,2 \text { e } j=1, \ldots, h \\
r=1, \ldots, R\end{array}$ & $\begin{array}{l}\text { Demanda pelo bem }(m 1) \text { utilizado como margem } \\
\text { para facilitar o fluxo de }(i s) \text { para (u) na região } r\end{array}$ \\
\hline$a_{(m 1)}^{(i s)(u) r}$ & $\begin{array}{l}m, i=1, \ldots, g ; s=1 b, 2 \text { para } \mathrm{b}=1, \ldots, q \\
(u)=(3),(4),(5),(6) \mathrm{e} \\
(k j) \text { para } k=1,2 \text { e } j=1, \ldots, h \\
r=1, \ldots, R\end{array}$ & $\begin{array}{l}\text { Mudança tecnológica relacionada a demanda pelo } \\
\text { bem }(m 1) \text { para ser utilizado como margem para } \\
\text { facilitar o fluxo de }(i s) \text { para }(u) \text { na região } r\end{array}$ \\
\hline$x_{(i 1)}^{(0 j) r}$ & $\begin{array}{l}i=1, \ldots, g ; j=1, \ldots, h \\
r=1, \ldots, R\end{array}$ & Produção do bem doméstico $i$ pela indústria $j$ \\
\hline$p_{(i s)}^{(0) r}$ & $\begin{array}{l}i=1, \ldots, g ; s=1 b, 2 \text { para } b=1, \ldots, \mathrm{q} \\
r=1, \ldots, \mathrm{R}\end{array}$ & Preço básico do bem i na região $r$ de origem $s$ \\
\hline$p_{(i(2)}^{(w)}$ & $i=1, \ldots, g$ & Preços CIF em US\$ do bem importado $i$ \\
\hline$t_{(i(2)}^{(0)}$ & $i=1, \ldots, g$ & Poder da tarifa sobre as importações de $i$ \\
\hline$t(\tau, i, s,(u) r)$ & $\begin{array}{l}i=1, \ldots, g ; \mathrm{t}=1, \ldots, t \\
s=1 b, 2 \text { para } b=1, \ldots, q \\
(u)=(3),(4),(5),(6) \\
\mathrm{e}(k j) \text { para } k=1,2 \text { e } j=1, \ldots, h \\
r=1, \ldots, R\end{array}$ & $\begin{array}{l}\text { Poder do imposto } \tau \text { nas vendas do bem }(i s) \text { para o } \\
\text { usuário }(u) \text { na região } r\end{array}$ \\
\hline$f_{(k)}^{(2 j) r}$ & $\begin{array}{l}j=1, \ldots, h \\
r=1, \ldots, R\end{array}$ & $\begin{array}{l}\text { Termo de deslocamento para o crescimento do es- } \\
\text { toque de capital de uma indústria regional específica }\end{array}$ \\
\hline
\end{tabular}




\begin{tabular}{|c|c|c|}
\hline Variáveis & Índices & Descrição \\
\hline$f_{(k)}^{r}$ & $r=1, \ldots, R$ & $\begin{array}{l}\text { Termo de deslocamento do estoque de capital na } \\
\text { região } r\end{array}$ \\
\hline$x_{(g+1,2)}^{(1 j) r}(1)$ & $\begin{array}{l}j=1, \ldots, h \\
r=1, \ldots, R\end{array}$ & $\begin{array}{l}\text { Estoque de capital na indústria } j \text { na região } r \text { ao final } \\
\text { do ano, i.e., estoque de capital disponível para uso } \\
\text { no período seguinte }\end{array}$ \\
\hline$p_{(k)}^{(1 j) r}$ & $\begin{array}{l}j=1, \ldots, h \\
r=1, \ldots, R\end{array}$ & $\begin{array}{l}\text { Custo de construção de uma unidade de capital } \\
\text { para a indústria } j \text { na região } r\end{array}$ \\
\hline$f_{(\tau)}$ & $\tau=1, \ldots, t$ & $\begin{array}{l}\text { Termo de deslocamento para variação porcentual } \\
\text { uniforme do poder do imposto } \tau\end{array}$ \\
\hline$f_{(\tau i)}$ & $\begin{array}{l}\tau=1, \ldots, t \\
i=1, \ldots, g\end{array}$ & $\begin{array}{l}\text { Termo de deslocamento para variação porcentual } \\
\text { uniforme do poder do imposto } \tau \text { sobre o bem } i\end{array}$ \\
\hline$f_{(\tau i)}^{(u)}$ & $\begin{array}{l}\tau=1, \ldots, t \\
(u)=(3),(4),(5),(6) \mathrm{e} \\
(k j) \text { para } k=1,2 \mathrm{e} j=1, \ldots, h\end{array}$ & $\begin{array}{l}\text { Termo de deslocamento para variação porcentual } \\
\text { uniforme do poder do imposto } \tau \text { sobre o bem } i \text { e } \\
\text { sobre o usuário }(u)\end{array}$ \\
\hline$f_{(\tau i)}^{(u) r}$ & $\begin{array}{l}\tau=1, \ldots, \mathrm{t} \\
(u)=(3),(4),(5),(6) \mathrm{e} \\
(k j) \operatorname{para} k=1,2 \mathrm{e} j=1, \ldots, h \\
r=1, \ldots, R\end{array}$ & $\begin{array}{l}\text { Termo de deslocamento para variação porcentual } \\
\text { uniforme do poder do imposto } \tau \text { sobre o bem } i \mathrm{e} \\
\text { sobre o usuário }(u) \text { na região } \mathrm{r}\end{array}$ \\
\hline$f_{(i s)}^{(5) r}$ & $\begin{array}{l}i=1, \ldots, g ; s=1 b, 2 \text { para } b=1, \ldots, q \\
r=1, \ldots, R\end{array}$ & $\begin{array}{l}\text { Termo de deslocamento por bem e origem especí- } \\
\text { fica dos gastos do governo regional na região } r\end{array}$ \\
\hline$f^{(5) r}$ & $r=1, \ldots, R$ & $\begin{array}{l}\text { Termo de deslocamento para os gastos do governo } \\
\text { regional na região } r\end{array}$ \\
\hline$f^{(5)}$ & & $\begin{array}{l}\text { Termo genérico de deslocamento dos gastos do } \\
\text { governo regional }\end{array}$ \\
\hline$f_{(i s)}^{(6) r}$ & $\begin{array}{l}i=1, \ldots, g ; s=1 b, 2 \text { para } b=1, \ldots, q \\
r=1, \ldots, R\end{array}$ & $\begin{array}{l}\text { Termo de deslocamento por bem e origem especí- } \\
\text { fica dos gastos do governo federal na região } r\end{array}$ \\
\hline$f^{(6) r}$ & $r=1, \ldots, R$ & $\begin{array}{l}\text { Termo de deslocamento para os gastos do governo } \\
\text { federal na região } r\end{array}$ \\
\hline$f^{(6)}$ & & $\begin{array}{l}\text { Termo genérico de deslocamento dos gastos do } \\
\text { governo federal }\end{array}$ \\
\hline$\omega$ & & Taxa de retorno do capital esperada (curto prazo) \\
\hline$r_{(j)}^{r}$ & $\begin{array}{l}j=1, \ldots, h \\
r=1, \ldots, R\end{array}$ & $\begin{array}{l}\text { Taxa de retorno do capital por região e indústria } \\
\text { específica }\end{array}$ \\
\hline
\end{tabular}


Parâmetros, Coeficientes e Conjuntos

\begin{tabular}{|c|c|}
\hline Símbolo & Descrição \\
\hline$\sigma_{(i)}^{(u) r}$ & $\begin{array}{l}\text { Parâmetro: elasticidade de substituição para o usuário }(u) \text { entre as origens alternativas do bem } \\
\text { ou fator } i \text { na região } r\end{array}$ \\
\hline$\sigma^{(0 j) r}$ & Parâmetro: elasticidade de transformação na indústria $j$ na produção de diferentes bens na região $r$ \\
\hline$\alpha_{(g+1, s)}^{(1 j) r}$ & Parâmetro: retornos de escala dos fatores primários na indústria $j$ na região $r$ \\
\hline$\beta_{(i)}^{r}$ & Parâmetro: participação marginal orçamentária no sistema linear de gastos do bem i na região $r$ \\
\hline$\gamma_{(i)}^{r}$ & Parâmetro: parâmetro de subsistência no sistema linear de gastos para o bem i na região $r$ \\
\hline$\varepsilon_{(j)}^{r}$ & $\begin{array}{l}\text { Parâmetro: sensibilidade do crescimento do estoque de capital a taxas de retorno na indústria } j \\
\text { na região } r\end{array}$ \\
\hline$\eta_{(i s)}^{r}$ & Parâmetro: elasticidade da demanda por exportação pelo bem i da região r. \\
\hline$\mu_{(i \bullet)}^{(u) r}$ & $\begin{array}{l}\text { Parâmetro: retornos de escala dos fatores primários }(i=g+1 \text { e } u=1 j) \text {; de outra forma, } \\
\mu_{(i \bullet)}^{(u) r}=1\end{array}$ \\
\hline$B(i, s,(u), r)$ & Fluxo de insumo-produto: valor básico de (is) utilizado por (u) na região r \\
\hline$M(m, i, s,(u), r)$ & $\begin{array}{l}\text { Fluxo de insumo-produto: valor básico dos bens domésticos } \mathrm{m} \text { utilizados como margens para } \\
\text { facilitar o transporte de }(i s) \text { para }(u) \text { na região } r\end{array}$ \\
\hline$T(\tau, i, s,(u), r)$ & Fluxo de insumo-produto: arrecadação de impostos $\tau$ sobre as vendas de $(i s)$ para $(u)$ na região $r$ \\
\hline$V(i, s,(u) r)$ & $\begin{array}{l}\text { Fluxo de insumo-produto: valor de compra do bem ou fator i da origem } s \text { utilizado pelo usuário } \\
(u) \text { na região } r\end{array}$ \\
\hline$Y(i, j, r)$ & Fluxo de insumo-produto: valor básico da produção do bem doméstico $i$ pela indústria $j$ da região $r$ \\
\hline$Q_{(j)}^{r}$ & Coeficiente: razão entre taxa de retorno bruta e líquida \\
\hline$G$ & Conjunto: $\{1,2, \ldots, g\}, g$ é o número de bens compostos \\
\hline$G^{*}$ & Conjunto: $\{1,2, \ldots, g+1\}, g+1$ é o número de bens compostos e fatores primários \\
\hline$H$ & Conjunto: $\{1,2, \ldots, h\}, h$ é o número de indústrias \\
\hline$U$ & Conjunto: $\{(3),(4),(5),(6),(\mathrm{kj})$ para $k=1,2 \mathrm{e} \mathrm{j}=1, \ldots, h\}$ \\
\hline$U^{*}$ & Conjunto: $\{(3),(k j)$ para $\mathrm{k}=1,2 \mathrm{e} j=1, \ldots, h\}$ \\
\hline$S$ & Conjunto: $\{1,2, \ldots, r+1\}, r+1$ é o número de regiões (incluindo setor externo) \\
\hline$S^{*}$ & Conjunto: $\{1,2, \ldots, r\}, r$ é o número de regiões domésticas \\
\hline$T$ & Conjunto: $\{1, \ldots, t\}, t$ é o número de impostos indiretos \\
\hline
\end{tabular}


Decomposição dos Subtotais (cf. Harrison et al., 1999)

Suponha a seguinte descrição de um modelo:

$Z=F(X, Y)(\mathrm{A} 3.1)$

onde $Z$ é uma variável endógena, e $X$ e $Y$ são variáveis exógenas.

Em um modelo aplicado, $Z$ representaria um vetor e poderia existir um número bem maior de variáveis exógenas. Entretanto, a análise deste modelo simplificado é útil o bastante para demonstrar como funciona a decomposição dos subtotais. Para uma pequena mudança em torno da solução inicial pode-se escrever a forma linearizada da seguinte maneira:

$\operatorname{delZ}=[F x] \operatorname{del} X+[F y] \operatorname{del} Y(\mathrm{~A} 3.2)$

onde $F x$ e $F y$ são as derivadas parciais de $F$ em relação a $X$ e $Y$.

Pode-se afirmar que $[F x]$ del $X$ é a parte de delZ devida a mudanças em $X$ e, de forma similar, $[F y]$ delY é a mudança em $Z$ devida a $Y$.

O software GEMPACK soluciona o sistema de equações não-lineares por meio de soluções repetidas de sistemas de equações semelhantes ao apresentado em (A3.2). As variações em $Z$, calculadas a cada passo em uma simulação em vários estágios, são acumuladas, e fornecem, assim, soluções mais acuradas. De forma similar, pode-se acumular os termos [Fx]delX e $[F y]$ delY para obter, então, as contribuições $C x$ e $C y$ de cada variável exógena. A soma das contribuições específicas igualar-se-á à variação total de $Z$.

Durante a solução do modelo, uma sucessão de pequenos choques em $\operatorname{del} X$ moverá $X$ de seu valor inicial, $X 0$, para o seu valor final, $X 1$. De forma similar, $Y$ deslocar-se-á de $Y 0$ para $Y 1$. Pode-se pensar no movimento destas duas variáveis exógenas como uma trajetória sobre um plano, de $[X 0, Y 0]$ para $[X 1, Y 1]$.

Claramente há diferentes trajetórias de $[X 0, Y 0]$ para $[X 1, Y 1]$. Felizmente, qualquer que seja a trajetória escolhida, uma vez que os passos individuais delX e delY sejam suficientemente pequenos, o valor correto da mudança em $Z$ será alcançado.

Entretanto, para modelos não-lineares, os valores das contribuições individuais acumuladas, $C x$ e $C y$, podem depender da trajetória seguida por $X$ e $Y$. Não obstante, a soma dessas contribuições não apresentará variações relevantes. 
A trajetória que o GEMPACK escolhe para as variáveis exógenas é uma linha reta entre os valores iniciais e valores finais das variáveis exógenas. Existem algumas razões teóricas que fogem ao escopo desta nota, para se supor que esta trajetória forneça estimativas menos viesadas de $C x$ e $C y$. 